

\title{
nombalina
}

\section{Sobre la identificación entre ébano y guayaco en una entrada del Index Dioscoridis de Amato Lusitano}

\author{
Autor(es): $\quad$ Miguel Mora, Carlos de \\ Publicado por: UA Editora - Universidade de Aveiro; Imprensa da Universidade de \\ URL \\ persistente: \\ Coimbra; Annablume \\ DOI: \\ URI:http://hdl.handle.net/10316.2/35699 \\ DOI:http://dx.doi.org/10.14195/978-989-26-0941-6_13 \\ Accessed : $\quad$ 26-Apr-2023 15:30:02
}

A navegação consulta e descarregamento dos títulos inseridos nas Bibliotecas Digitais UC Digitalis, UC Pombalina e UC Impactum, pressupõem a aceitação plena e sem reservas dos Termos e Condições de Uso destas Bibliotecas Digitais, disponíveis em https://digitalis.uc.pt/pt-pt/termos.

Conforme exposto nos referidos Termos e Condições de Uso, o descarregamento de títulos de acesso restrito requer uma licença válida de autorização devendo o utilizador aceder ao(s) documento(s) a partir de um endereço de IP da instituição detentora da supramencionada licença.

Ao utilizador é apenas permitido o descarregamento para uso pessoal, pelo que o emprego do(s) título(s) descarregado(s) para outro fim, designadamente comercial, carece de autorização do respetivo autor ou editor da obra.

Na medida em que todas as obras da UC Digitalis se encontram protegidas pelo Código do Direito de Autor e Direitos Conexos e demais legislação aplicável, toda a cópia, parcial ou total, deste documento, nos casos em que é legalmente admitida, deverá conter ou fazer-se acompanhar por este aviso.

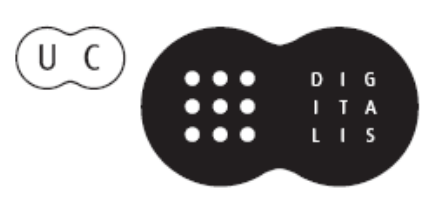




\section{HUMANISMO E CIÊNCIA Antiguidade e Renascimento}

António Manuel Lopes Andrade

Carlos de Miguel Mora

João Manuel Nunes Torrão
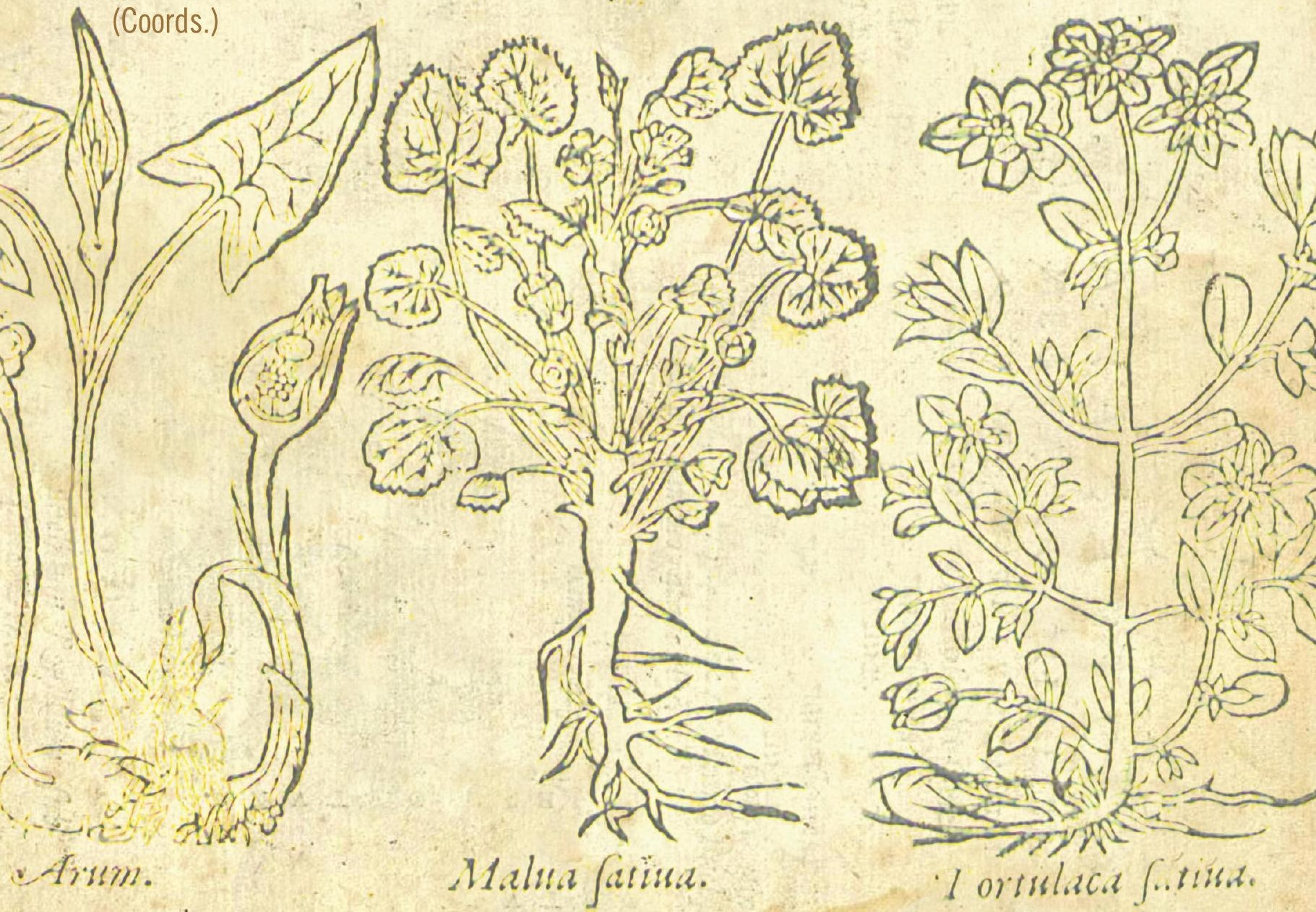

Aveiro I Coimbra I São Paulo 2015

UA Editora - Universidade de Aveiro I Imprensa da Universidade de Coimbra I Annablume 
Este volume resulta de várias iniciativas desenvolvidas no âmbito do projecto de I\&D "Dioscórides e o Humanismo Português: os Comentários de Amato Lusitano" (http://amatolusitano.web.ua.pt), recoIhendo contribuições de mais de duas dezenas de colaboradores, tanto de membros da equipa como de outros investigadores nacionais e estrangeiros. Entre os eventos que estiveram na origem deste livro destacam-se as três edições do Ciclo de Conferências promovido pelo projecto, realizadas entre 2010 e 2013, e sobretudo o Colóquio Internacional "Dioscórides e o Humanismo Português: os Comentários de Amato Lusitano", que decorreu no Departamento de Línguas e Culturas da Universidade de Aveiro, nos dias 21 e 22 de Novembro de 2013.

0 objectivo principal do projecto é a edição e tradução para português dos dois livros que Amato Lusitano dedicou ao comentário do tratado grego De materia medica de Dioscórides, ou seja, o Index Dioscoridis (Antuérpia, 1536) e as In Dioscoridlis Anazarbei de medica materia libros quinque... enarrationes (Veneza, 1553), estando contemplada, também, a tradução de mais duas obras directamente correlacionadas com os livros do médico português: a montante, a do próprio tratado grego de Dioscórides; a jusante, a do livro intitulado Apologia adversus Amathum Lusitanum (Veneza, 1558) de Pietro Andrea Mattioli.

OBRA PUBLICADA COM A COORDENAÇÃO

CIENTÍFICA DE:

Centro de Línguas, Literaturas e Culturas da Universidade de Aveiro

Centro de Estudos Clássicos e Humanísticos da Universidade de Coimbra

Cátedra de Estudos Sefarditas "Alberto

Benveniste" da Faculdade de Letras da Universidade de Lisboa 


\section{HUMANISMO E CIÊNCIA}

\section{Antiguidade e Renascimento}

ANTÓNIO MANUEL LOPES ANDRADE

CARLOS DE MIGUEL MORA

JOÃO MANUEL NUNES TORRÃO

(COORDS.)

AVEIRO • COIMBRA • SÃO PAULO

2015

UA EDITORA • UNIVERSIDADE DE AVEIRO

IMPRENSA DA UNIVERSIDADE DE COIMBRA

ANNABLUME 


\section{HUMANISMO E CIÊNCIA: Antiguidade e Renascimento}

\author{
EDIÇÃO

UA EDITORA • UNIVERSIDADE DE AVEIRO
IMPRENSA DA UNIVERSIDADE DE COIMBRA
ANNABLUME

ORGANIZAÇÃO E COORDENAÇÃO EDITORIAL ANTÓNIO MANUEL LOPES ANDRADE

CARLOS DE MIGUEL MORA

JOÃO MANUEL NUNES TORRÃO

\author{
DESIGN DA CAPA \\ MEIOKILO DESIGN STUDIO
}

DESIGN

CARLOS COSTA

IMPRESSÃO E ACABAMENTO

SERSILITO • MAIA

ISBN

UA • 978-972-789-434-5

IUC • 978-989-26-0940-9

\section{ISBN DIGITAL}

UA • 978-972-789-435-2

IUC • 978-989-26-0941-6

DOI

http://dx.doi.org/10.14195/ 978-989-26-0941-6

DEPÓSITO LEGAL 368241/13

TIRAGEM 500 Exemplares

(C) 2015

UA EDITORA • UNIVERSIDADE DE AVEIRO IMPRENSA DA UNIVERSIDADE DE COIMBRA

ANNABLUME

\section{COMISSÃO CIENTÍFICA}

António Manuel Lopes Andrade

Carlos de Miguel Mora

Delfim Ferreira Leão

Henrique Leitão

João Manuel Nunes Torrão

Maria de Fátima Reis

Maria do Céu Zambujo Fialho

Miguel Ángel González Manjarrés

\section{TEXTOS}

Adelino Cardoso

Ana Leonor Pereira

Ana Margarida Borges

António Guimarães Pinto

António Maria Martins Melo

Bernardo Mota

Carlos A. Martins de Jesus

Carlos de Miguel Mora

Cristina Santos Pinheiro

Donald Beecher

Emília Oliveira

Isabel Malaquias

James W. Nelson Novoa

Joana Mestre Costa

João Manuel Nunes Torrão

João Rui Pita

Jorge Paiva

José Sílvio Moreira Fernandes

Maria de Fátima Silva

Miguel Ángel González Manjarrés

Rui Manuel Loureiro

Telmo Corujo dos Reis

Teresa Nobre de Carvalho

Vinicije B. Lupis

Virgínia Soares Pereira 


\section{HUMANISMO E CIÊNCIA}

\section{Antiguidade e Renascimento}

ANTÓNIO MANUEL LOPES ANDRADE

CARLOS DE MIGUEL MORA

JOÃO MANUEL NUNES TORRÃO

(COORDS.)

AVEIRO • COIMBRA • SÃO PAULO

2015

UA EDITORA • UNIVERSIDADE DE AVEIRO

IMPRENSA DA UNIVERSIDADE DE COIMBRA

ANNABLUME 
OBRA PUBLICADA

COM A COORDENAÇÃO

CIENTÍFICA DE:

CENTRO DE LÍNGUAS,

LITERATURAS E CULTURAS DA

UNIVERSIDADE DE AVEIRO

CENTRO DE ESTUDOS

CLÁSSICOS E HUMANÍSTICOS DA

UNIVERSIDADE DE COIMBRA

CÁTEDRA DE ESTUDOS SEFARDITAS

"ALBERTO BENVENISTE"

DA FACULDADE DE LETRAS DA

UNIVERSIDADE DE LISBOA 


\section{SUMÁRIO}

PREFÁCIO

1.1 "Teofrasto, Tratado das plantas. No alvor de uma nova ciência" 13

Maria de Fátima Silva

1.2 "Francisco de Melo e os fragmentos de teoria óptica de Pierre Brissot" 21 Bernardo Mota

1.3 "Algumas reflexões sobre as pedras preciosas nos Colóquios dos simples de Garcia de Orta" 37 Rui Manuel Loureiro

1.4 "Estratégias, patronos e favores em Colóquios dos Simples de Garcia de Orta" 63 Teresa Nobre de Carvalho

1.5 "As plantas na obra poética de Camões (épica e lírica)" 95 Jorge Paiva

1.6 "Nicolás Monardes, John Frampton and the Medical Wonders of the New World" .141 Donald Beecher

1.7 "Literatura e Medicina: alguns textos de Justo Lípsio e de dois doutores Luís Nunes" 161 António Guimarães Pinto

1.8 "Ontologias e idiossincrasias dos Amantes, à luz da Archipathologia de Filipe Montalto" ...... 211 Joana Mestre Costa \& Adelino Cardoso

1.9 "Gabriel da Fonseca. A New Christian doctor in Bernini's Rome". .227 James W. Nelson Novoa 


\section{2) DIOSCÓRIDES E O HUMANISMO PORTUGUÊS: OS COMENTÁRIOS DE AMATO LUSITANO}

2.1 "Léxico científico português nos Comentários de Amato: antecedentes e receção"

Ana Margarida Borges

2.2 "Usos medicinais das plantas, em Amato Lusitano: o bálsamo"

António Maria Martins Melo

2.3 "Amato Lusitano e a importância da ilustração botânica no século xVI.

Em torno das edições lionesas das Enarrationes (1558)"

Carlos A. Martins de Jesus

2.4 "Sobre la identificación entre ébano y guayaco en una entrada

del Index Dioscoridis de Amato Lusitano".

Carlos de Miguel Mora

2.5 "Os partos distócicos em Amato Lusitano e em Rodrigo de Castro:

fontes, doutrinas e terapias greco-romanas"

\section{Cristina Santos Pinheiro}

2.6 "Do carvalho ao castanheiro: usos e propriedades medicinais

de fagáceas nas Enarrationes de Amato Lusitano".

Emília Oliveira

2.7 "O mundo mineral nos Comentários a Dioscórides de Amato Lusitano".

Isabel Malaquias \& Virgínia Soares Pereira

2.8 "Alguns comentários de Amato: entre a estranheza e a realidade"

João Manuel Nunes Torrão

2.9 "Caracterização e usos terapêuticos de produtos de origem marinha

nos Comentários de Amato Lusitano a Dioscórides"

José Sílvio Moreira Fernandes

2.10 "La mandrágora de Amato Lusitano: edición, traducción y anotación"

Miguel Ángel González Manjarrés

2.11 "O vinho e os vinhos - usos e virtudes de um dom dos deuses

nas Enarrationes de Amato Lusitano"

Telmo Corujo dos Reis

2.12 "Amatus Lusitanus e Didaco Pirro: due ebrei portoghesi

e cerchia umanistica di Dubrovnik" 481

Vinicije B. Lupis

2.13 "Estudos contemporâneos sobre Amato Lusitano". 513

João Rui Pita \& Ana Leonor Pereira 


\title{
Sobre la identificación entre ébano y guayaco en una entrada del Index Dioscoridis de Amato Lusitano ${ }^{1}$
}

\author{
CARLOS DE MIGUEL MORA²
}

\section{RESUMEN:}

En el presente artículo pretendemos descubrir cómo se encuadra el primer comentario de Amato Lusitano a la materia médica de Dioscórides, el Index Dioscoridis, en el proceso de confusión entre el guayaco y el ébano que se sabe que se produjo a principios del s. xVI. Para ello, intentamos revisar en primer lugar cómo surge la enfermedad del mal francés, para llegar a la conclusión de que la novedad del mal exigió, en cierto modo, un tratamiento también novedoso, en este caso por guayaco, madera procedente de las llamadas Indias occidentales. Aunque la información sobre plantas iba llegando del nuevo mundo, el desconocimiento del guayaco y, lo que es más sorprendente, el aparente desconocimiento del ébano a no ser por las descripciones de los autores antiguos, permitió una confusión que fue acentuada por cuestiones económicas (el control de unas pocas familias sobre el mercado del guayaco) y las propias características de la historia natural en el Renacimiento. A continuación, se analizan paso a paso algunos textos que permiten comprender la evolución de la comparación entre el guayaco y el ébano, para llegar al texto del Index de Amato, que supone un cambio de paradigma por la convicción y los argumentos con que defendió la postura de la identidad entre ambas especies.

\section{Palabras clave:}

Humanismo médico; mal francés; sífilis; guayaco; ébano; plantas del nuevo mundo; Amato Lusitano.

1 Trabajo realizado en el ámbito del proyecto de I+D "Dioscórides e o Humanismo Português: os Comentários de Amato Lusitano" (http://amatolusitano.web.ua.pt) del Centro de Línguas, Literaturas e Culturas de la Universidad de Aveiro, financiado por Fondos FEDER a través del Programa Operacional Factores de Competitividade - COMPETE y por Fondos Nacionales a través de la FCT - Fundação para a Ciência e a Tecnologia, en el ámbito do proyecto FCOMP-01-0124-FEDER-009102.

2 Centro de Línguas, Literaturas e Culturas da Universidade de Aveiro: cmm@ua.pt. 


\begin{abstract}
:
In this article we explore how the Index Dioscoridis, the first commentary by Amatus Lusitanus on Dioscorides' work on materia medica, contributes to the confusion between guaiac and ebony which, as is well known, was produced at the beginning of $16^{\text {th }}$ century. To do this, we first endeavour to explore how the French disease appears, to conclude that the novelty of the disease demanded, in like measure, an equally novel treatment, in this case the application of guaiac, from the so-called West Indies. Although information on plants was arriving from the new world, the unavailability of guaiac and, what is more surprising, the apparent lack of knowledge about ebony, but for the descriptions provided by ancient authors, allowed for a confusion which was further intensified by economic issues (the control of the guaiac market by a few families) and the characteristics of natural history in the Renaissance. We then analyze some texts that allow us to understand the evolution of the comparison between guaiac and ebony, step by step, in order to arrive at the Index of Amato, which represents a radical paradigm shift due to his convictions and to the arguments with which he defends the position of the identity of the two species.
\end{abstract}

\title{
KEYWORDS:
}

Medical Humanism; French disease; syphilis; guaiac; ebony; plants from de new world; Amatus Lusitanus. 


\section{LA APARICIÓN DEL MAL FRANCÉS}

En la última década del s. xv proliferan las descripciones de una enfermedad que casi todos, tanto los expertos como el público en general, consideran nueva. Los testimonios de que disponemos sitúan la primera aparición de este mal en el año 1494, y muy probablemente en el entorno de Nápoles, en el momento en que esta ciudad se hallaba asediada por las tropas del monarca francés Carlos VIII, al inicio de lo que después se conoció como Guerras Italianas. Que la enfermedad, rápidamente extendida por todo el mundo, fuese catalogada como 'nueva' suponía un serio problema para el estamento médico. Los médicos, a diferencia de empíricos, cirujanos, barberos y otros sanadores sin estudios teóricos, basaban su prestigio en unos conocimientos heredados de la antigüedad y recientemente purgados del oscurantismo medieval por el movimiento humanista (al menos, esta era la imagen que interesaba transmitir); este conocimiento y el manejo de vocabulario y conceptos complejos, como las teorías galénicas de los temperamentos, garantizaban el control en exclusiva de los complicados y caros procedimientos terapéuticos que se debían aplicar en determinadas enfermedades. Sin embargo, a despecho de algunas voces disonantes que reclamaron que la enfermedad ya era conocida desde la Antigüedad grecolatina, lo cierto es que la mayor parte de los primeros textos pregonaba la novedad de la misma. Así, por ejemplo, en septiembre de 1496, Piero di Marco Parenti, en el segundo tomo de sus Istorie Fiorentini, dice "Non sarà inconueniente far memoria della nuoua malattia uenuta in Italia a questi tempi, chiamata rogna franciosa la quale in tutte le parti del mondo si distese."3 Segismundo Titio, en el tomo VI (p. 439 sub anno 1497) de sus Historiarum Senensium ab initio Urbis Senarum usque ad annum 1528, afirma: "Advenere praeterea hoc anno 1497 novi ac insoliti hominibus morbi pustulis primum in facie, modo vero in toto corpore... (...) Quem egritudinem aevo nostro amplius non visam, ex adventu Gallorum morbum gallicum appellant." 4

Se podrían multiplicar los ejemplos de este tipo de afirmaciones, pero nos fijaremos tan solo en otros dos textos que demuestran que la novedad estaba muy relacionada con la falta de reconocimiento por parte de los médicos. El hecho de no identificar una enfermedad anulaba

3 Fuente de inapreciable valor para estudiar los primeros testimonios sobre el mal francés es la obra de Alfonso CORRADI, Nuovi documenti per la storia delle malattie veneree in Italia dalla fine del Quatrocento alla metà del Cinquecento. Milano, Tipografia Fratelli Rechiedei, 1884. En ella se encuentra un buen número de documentos inéditos y publicados sobre esta temática. Aunque con posterioridad a la obra de Corradi se han publicado algunos de los inéditos, esta sigue siendo imprescindible para una aproximación a las primeras reacciones ante el mal francés. La obra de Parenti estaba inédita entonces, aunque en la actualidad ha sido publicada por Andrea Matucci (Piero di Marco PARENTI, Storia fiorentina, I, 1476-1478, 1492-1496, a cura di A. MatuccI. Firenze, Leo S. Olschki Editore, 1994; Piero di Marco ParentI, Storia fiorentina, II, 1496-1502, a cura di A. MATUCCI. Firenze, Leo S. Olschki Editore, 2005). La cita está tomada de Alfonso CorRADI, Nuovi documenti..., op. cit., p. 56. La cursiva es nuestra.

4 Ibidem. 
por completo la competencia del médico, ya que su saber estaba directamente vinculado a la aplicación de remedios específicos adecuados para un tipo particular de dolencia. El desconocimiento provoca la falta de esperanza en la cura y, por lo tanto, un agravamiento de índole psicosomático en la condición del paciente, aparte de un sentimiento alarmista en la sociedad en general. El primero de estos textos, escrito en 1501, es de Nadi Gaspare, de su Libro per tenere Ricordo dal 1418 al 1501: "Rechordo, chome uenne uno Morbo a Bologna, e per el quale ueniua alle persone una malatia doglie in le chonzeture e bole per adosso portauano una grandissima passion specialmente la notte, cridauano che iera (era) una gran passion, non se trouaua medise (medico) che lo conoscesse, se chiamaua male franzoso comezò dell'anno 1495, e ancora iera dell'anno 1496 e dell'anno 1497." 5 El segundo, de Friano degli Ubaldini, lo extrajo Corradi de la Cronaca dalla creazione del mondo fino all'anno di N. S. 1513, nella quale non lascia di scrivere tutta l'istoria della sua Patria, T. III dall'anno 1492 fino a tutto il 1513, p.717, y en él se puede leer lo siguiente: "Esendo uenuto el Re Charlo de Franza in Italia chome e dito per andare a piare el Reamo de napuli chomenzo auenire aliomeni e ale done una strania et oribile malatia la quale non era archognessuta (riconosciuta) da medico alchuno e le persone dezevano che li franzoxi aueano portado la dicta malatia in italia e fuli posto nomo male franzoxo." La idea de que le enfermedad era totalmente nueva y, por ende, incurable (al no poderse encontrar un remedio apropiado) se encuentra en muchos otros textos. Pero vale la pena mencionar dos textos literarios espańoles, escritos por estudiosos de la medicina, que se hacen eco de esta idea. El primero, de 1498, es de Francisco López de Villalobos, quien, en la tercera estrofa de su Sobre las contagiosas y malditas buvas estoria y melecina, poema incorporado a su Sumario de la medicina en romance trovado con un tratado sobre las pestiferas bubas por el licenciado Villalobos, estudiante en el estudio de Salamanca hecho a contemplación del muy magnifico y ilustre señor el marques de Astorga, publicado en Salamanca, dice:

\footnotetext{
Fue una pestilencia no vista jamas

en metro ni en prosa ni en sciencia ni estoria

muy mala y perversa y cruel sin compas

muy contagiosa y muy suzia en demas

muy brava y con quien no se alcanza vitoria

la qual hace al hombre indispuesto y gibado

la qual en mancar y doler tiene extremos

la qual escurece el color aclarado
}

\footnotetext{
5 Alfonso CoRRADI, Nuovi documenti..., op. cit., pp. 58-59. El autor informa que recoge el texto de un manuscrito de la Biblioteca de la Universidad de Bolonia. Las cursivas que no están entre paréntesis son nuestras.

6 Alfonso CorRADI, Nuovi documenti..., op. cit., p. 59.
} 
es muy gran vellaca y asi á comenzado

por el mas vellaco lugar que tenemos ${ }^{7}$

El segundo es de Francisco Delgado, quien, en su Lozana Andaluza, obra publicada en Venecia en $1528^{8}$, indica en un diálogo la poca confianza que tiene el pueblo en poder sanar de esta dolencia:

COR. ¿Qué podria decir como ignorante?

LOZ. Di que sanarás el mal frances, y te judicarán por loco del todo, que ésta es la mayor locura que uno puede decir. ${ }^{9}$

Los médicos, evidentemente, no podían aceptar sin más la novedad del mal, lo que hubiera significado, como se deduce claramente de los textos, la imposibilidad de tratarlo. De hecho, el debate que se originó en un principio, y que fue el motivo principal de la llamada "disputa de Ferrara" 10 , fue determinar si lo que empezaba a ser conocido principalmente bajo la denominación de 'mal francés' se correspondía en realidad con alguna enfermedad antigua ya conocida o si, por el contrario, había surgido como algo totalmente nuevo. Las conjeturas sobre su procedencia y, desde luego, la teoría del origen americano, solo vendrían posteriormente, cuando se acabe por imponer la tesis de su novedad ${ }^{11}$.

7 Extraido de Anastasio CHINCHILLA, Anales históricos de la medicina en general y biográfico-bibliográficos de la española en particular, Tomo I. Valencia, Imprenta de López y Compañía, 1841, p. 105-106. He corregido el final del tercer verso, donde aparece copas por evidente errata, ya que incluso impide la rima. Existe una edición moderna de María Teresa Herrera, publicada en Salamanca en 1973. Chinchilla transcribe todo el poema entre las páginas 105 y 126.

8 En el finis el autor fecha la conclusión de la obra en 1524, pero los certeros vaticinios de acontecimientos de 1527 sugieren más de una redacción. Cf. Tatiana Bubnova, "Delicado en la Peña de Martos", en Jules WHICKER, Actas del XII Congreso de la Asociación Internacional de Hispanistas 21-26 de agosto de 1995, Vol. 2: Estudios áureos I. Birmingham, University of Birmingham, 1998, pp. 70-78.

Disponible en http://cvc.cervantes.es/literatura/aih/pdf/12/aih_12_2_011.pdf.

9 Mamotreto 55. Cito por Francisco DeLGADo, Retrato de la lozana andaluza. Madrid, Imprenta y Estereotipia de M. Rivadeneyra, 1871, p. 280.

10 Como demostró Jon Arrizabalaga, "Sebastiano dall'Aquila (c. 1440 - c. 1510), el 'mal francés' y la 'disputa de Ferrara' (1497)", DYNAMIS. Acta Hispanica ad Medicinae Scientiarumque Historiam Illustrandam 14 (1994), pp. 227-247, esta disputa se realizó de forma física, es decir, como una reunión y no como un intercambio de escritos, tuvo lugar en alguna de las dependencias de la corte de los duques de Este, en lugar de las tradicionales reuniones en un Studium generale dentro del ámbito académico, y tuvo como esencial propósito debatir si el mal francés que asolaba la ciudad podía ser identificado, como algunos decían, con la elefantiasis.

11 Cf. Jon Arrizabalaga, John Henderson \& Roger French, The Great Pox. The French Disease in Renaissance Europe. New Haven and London, Yale University Press, 1997, pp. 24-25. 
De hecho, Villalobos y Delgado muestran posiciones diferentes. El primero, en su calidad de médico, afirma la novedad solo de forma aparente, pues más adelante en su tratado, en la estrofa 27 , acaba por identificar la enfermedad con otra antigua, la sarna egipcia: ${ }^{12}$

\footnotetext{
Y pues tan probado esta mi propuesto no quiero altercar mas en esta escritura y de aqueste morbo questa presupuesto agora sea puesto en scabie o no puesto el nombre dire y la passion y la cura aquesta segun mi razon corta y flaca que alos que pecaron tan crudo condena debemos nombrarla la sarna egipciaca que asi es tan perversa y vellaca enbiada de Dios por castigo y por pena. ${ }^{13}$
}

De ese modo puede, a continuación, recomendar las recetas y los cuidados que se han de tener para mejorar en esta enfermedad. En cambio, el práctico (médico empírico) Delgado, no tiene necesidad de identificarla con otra. Lo que hace es proponer en su obra, por un lado, remedios caseros y, por otro, el tratamiento a base de leńo santo o guayaco ${ }^{14}$, cosa que le interesa, por haber sido probablemente uno de los primeros que lo introdujo en Italia y por ser autor de un opúsculo sobre el tratamiento del mal francés por medio de ese producto americano. ${ }^{15}$

En realidad, una de las características más notorias de este mal, la profusión de nombres con que se lo conoce, deriva en parte de esta controversia inicial y del intento de identificarlo con otras enfermedades conocidas, lo que llevó a términos como elephantiasis, lichen, mentagra carbonem o ignem persicum. Pero incluso aquellos que veían en ella una enfermedad totalmente nueva multiplicaron los intentos de nombrarla, en parte para evitar el término que se había extendido de forma vulgar, mal francés, puesto que suponía una comprensible ofensa para los

12 Por cierto, el mencionado Segismundo Titio afirma que el mal francés es diferente y peor que la piaga egiziaca y que la mentagra di Plinio. Cf. Alfonso CoRRADI, Nuovi documenti..., op. cit., p. 57.

13 Anastasio ChINCHILLA, Anales históricos..., op. cit., pp. 112-113.

14 Cf. Ma Cruz Herrero Ingelmo; Enrique Montero Cartelle, "El Morbus gallicus o Mal francés en La Lozana andaluza de Francisco Delicado", Asclepio 65, 2 (julio-diciembre 2013), p021. http://dx.doi. org/10.3989/asclepio.2013.21. De hecho, el texto completo de la intervención de la lozana andaluza que hemos transcrito anteriormente, es el siguiente: "Di que sanarás el mal frances, y te judicarán por loco del todo, que ésta es la mayor locura que uno puede decir, salvo que el legño es salutífero."

15 El modo de adoperare el legno de India Occidentale. Salutífero remedio a ogni piaga et mal incurabile, Roma 1525. Hemos consultado la edición de Bruno M. DAMIANI, "Francisco Delicado El modo de adoperare el legno de India Occidentale. A critical transcription", Revista Hispánica Moderna 36, no 4 (1970/1971), pp. 251-271. 
franceses ${ }^{16}$. Esta búsqueda de un término neutro originó las denominaciones más variopintas, ya se decantasen por hacer referencia a una enfermedad con que se pareciera (como crassiora variola), ya por mencionar una parte del cuerpo (como mentulagra o inguinagra), ya por alguna característica de su contagio (como mal de siment) ${ }^{17}$, ya por el supuesto origen astrológico (como saturninum morbum), etc. ${ }^{18}$

El nombre más curioso fue, con toda probabilidad, el que le atribuyó el médico, filósofo y filólogo Girolamo Fracastoro, sifilis, que fue el que a la postre acabaría por triunfar ${ }^{19}$. Pero para ello tendrían que pasar siglos, pues esta designación no se empezó a usar hasta bien entrado el siglo XVIII. En cualquier caso, es necesario emplear esta terminología con cautela cuando se habla de la historia de una enfermedad pues, tal como alertan los autores Arrizabalaga, Henderson y French ${ }^{20}$, no se puede decir que la sífilis actual sea la misma enfermedad que el mal francés. Una enfermedad es un concepto abstracto fruto del cruce de varios elementos (formas de contagio, posible parásito -en caso de las enfermedades infecciosas-, etiología, síntomas, pacientes...). La medicina actual aplica unos criterios de definición que no son idénticos a los de épocas anteriores y, por lo tanto, a lo más que podemos aspirar es a estudiar el concepto de sífilis y no la enfermedad en $s^{21}$.

16 Hutten, por ejemplo, siente la necesidad de disculparse por utilizar ese nombre en aras de la claridad: Ulrich von HUTTEN, De guaiaci medicina et morbo Gallico liber unus. [Parisiis], Ex typis Petri Vidoue, 1519, fol. aiii (De morbi Gallici ortu et nomine Caput I): "nos hoc opusculo Gallicum dicemus, non inuidia quidem gentis clarissimae et qua uix alia sit hoc tempore ciuilior aut hospitalior, sed ueriti ne non satis intelligant omnes, si quolibet alio nomine rem signemus."

17 Aunque en este caso es dudoso que se refiera a simiente. Para una sólida justificación de que se podría estar haciendo referencia a un santo bretón, saint-Méen-le-Grand, ver Germán Colón DOMÉNECH, "Filología y sífilis. Sobre el mal de simiente o mal de sement", Revista de Filología Española $78,3^{\circ}-4^{\circ}$ (julio-diciembre de 1998), pp. 275-308.

18 Para hacerse una idea de la multiplicidad de nombres usados para designar esta afección, se puede ver, por ejemplo, el texto reciente de Danielle GOUREVITCH, "La syphilis, une maladie aux noms multiples" en Jerôme FrACASTOR, La syphilis ou le mal français. Syphilis sive Morbus Gallicus, Texte établi, traduit, présenté et annoté sous la direction de Jacqueline Vons, avec la collaboration de Concetta PenNuto et Danielle Gourevitch et le concours du Dr. Jacques Chevallier. Paris, Les Belles Lettres, 2011, pp. XV-XXXVII. Aunque sea más antiguo, parece más claro en su exposición el artículo de Ma Jesús PÉrEZ IBÁÑEZ, "Un problema médico y terminológico (sífilis en el s. XVI)", Voces 6 (1995), pp. 61-79. La misma autora trabaja sobre un término eufemístico en "Galli vocant istum morbum morbum eius cuius est. Otra designación para el 'mal francés'", Asclepio. Revista de Historia de la Medicina y de la Ciencia $40-n^{\circ} 1$ (enero-junio 2008), pp. 267-280. Un estudio también reciente es el de Antonio TAGARELLI, Giuseppe Tagarelli, Paolo Lagonia, Anna Piro, "A Brief History of Syphilis by Its Synonyms", Acta Dermatovenerol Croat 19- 4 (2011), pp. 228-236, aunque no introduce algunas conclusiones de Pérez Ibáñez.

19 Hieronymus Fracastorius, Syphilis siue Morbus Gallicus. Verona [Stefano Nicolini da Sabbio e fratelli] 1530. La edición con traducción más reciente es la citada Jerôme FRACASTOR, La syphilis ou le mal français.

20 Jon Arrizabalaga, John Henderson \& Roger French, The Great Pox..., op. cit., pp. 1-3.

21 Jon Arrizabalaga, "Syphilis", The Cambridge World History of Human Disease. $1^{\text {st }}$ ed. Cambridge, Cambridge University Press, 1993, pp. 1025-1033. Cambridge Histories Online. Accedido el 14 de marzo de 2013. http://dx.doi.org/10.1017/CHOL9780521332866, maxime p. 1029. 


\section{LOS TRATAMIENTOS DE LA ENFERMEDAD}

No aceptar la novedad de la dolencia, como decíamos, facilitaba la posibilidad de tratarla, pues al identificarla con otra se podían prescribir los mismos remedios transmitidos por la tradición. Es el caso de Gaspar Torrella y Pere Pintor, médicos valencianos en la corte de Alejandro VI. Jon Arrizabalaga ${ }^{22}$ demostró que ambos, a raíz de su identificación con diferentes enfermedades (una especie de aluhumata o viruela corruptiva en el caso de Pere Pintor, sarna — scabies— para Torrella), consideraron diferentes modos de contagio y aplicaron tratamientos diferenciados. Cuando, poco a poco, se empezó a hacer evidente que el llamado 'mal francés' no podía ser asimilado con propiedad a ninguna de las enfermedades de que se tenía constancia en la historia de la medicina, también los médicos de prestigio anunciaron su carácter novedoso. Por poner un ejemplo que contrasta claramente con los médicos valencianos Torrella y Pintor, unos años más tarde otro médico de la corte papal, en este caso médico personal del papa Julio II, Giovanni de Vigo, quien introduce unos comentarios sobre el mal francés en su Practica in arte chirurgica copiosa continens nouem libros (Romae, per S. Guillireti et H. Bononiensem, 1514), afirma: "Et propterea sicut ista aegritudo est incognita et nunquam a doctoribus uisa prout nunc est" Por ese motivo, tiene que declarar más adelante que para su curación fue necesario investigar métodos terapéuticos nuevos, y que si alguna cosa trajo provecho fue más a raíz de nuevos experimentos que de antiguos remedios: "Ideo pro eius curatione operae precium fuit noua auxilia et pharmaca indagare. Et in rei ueritate, si quid salutis inuentum fuerit in isto morbo, fuit id potius ex nouis experimentis, quam ex antiquis auxilijs." Un poco más adelante anunciará ese nuevo método, producto de los recientes experimentos. Junto a complejos brebajes y regímenes especiales transmitidos por la tradición, se puede sanar a partir de una simple untura reforzada con un poco de mercurio ("ex simplici unctione cum modico argenti uiui roborata") ${ }^{24}$.

Este caso específico nos sirve de ejemplo de aquello que se dio en general en todo el ambiente médico de la época a la hora de enfrentarse al mal francés. A unos primeros tratamientos basados en las recetas tradicionales (sangrías, baños de vino y hierbas o de aceite, regímenes, cauterización, estufas de calor, emplastos y diversos brebajes) se siguió, como remedio más específico, el tratamiento por mercurio, normalmente en unciones ${ }^{25}$. En realidad, el mercurio

22 Jon ArrizabalaGa, "Práctica y teoría en la medicina universitaria de finales del siglo xv: el tratamiento del mal francés en la corte papal de Alejandro VI Borgia", Arbor 153, n 604-605 (Abril-Mayo 1996), pp. 127-160.

23 Giovanni de Vico, De morbo gallico en Luisinus, 1566, vol. I, p. 387. Cito por la edición de Aloysius LUISINUS, De morbo gallico omnia quae extant apud omnes medicos cuiusque nationis, tomus prior. Venetiis, apud lordanum Zilettum, 1566.

24 Ibidem.

25 Se puede ver un buen resumen de estos tratamientos en Jon ARRIZABALAGA, John Henderson \& Roger FRENCH, The Great Pox..., op. cit., pp. 28-32 y después, centrado en la corte papal pero con mucho mayor detalle, en 131-142. 
era un tratamiento ya usado para enfermedades que producían llagas en la piel, como la sarna, y gozaba de tradición galénica, por lo que en realidad se trataba de la aplicación de un tratamiento antiguo por aproximación, por la semejanza entre los síntomas externos de las dolencias.

Como en un principio parecía el único remedio que surtía algún efecto, pronto se convirtió en el tratamiento por antonomasia contra el mal francés ${ }^{26}$, para suplicio de los enfermos, pues los terribles dolores que causaba, la hediondez del aliento, la pérdida de dientes, eran un castigo tan terrible que muchos afirmaban que preferían morir por el mal francés que vivir con el mercurio. Además, como notaron muchos médicos ${ }^{27}$, la enfermedad había cambiado durante las primeras dos décadas, y ya no era tan mortal. Sirvan de ejemplo estas palabras de Fracastoro, escritas en 1546:

\begin{abstract}
Abinde enim annis fere viginti coeperunt pauciores videri pustulae, gummositates vero plures, quum e contrario primis annis fuisset, factae item fuere pustulae (si quae apparebant) sicciores, ac dolores (si qui accedebant) cuivis sunt acerbiores. Porro et annis labentibus, annis iam fere sex in quibus nunc sumus, magna rursus mutatio facta est eius morbi; quippe quum in valde paucis pustulae iam visantur, et dolores fere nulli, aut multo leviores, gummositates vero multae, et, quod mirum omnibus visum est, capillorum, et reliquorum pilorum casus homines fere ridiculos facit, aliis sine barba, aliis sine superciliis, aliis glabro capite in conspectum venientibus, quod infortunium prius putabatur ex medicaminibus evenire, praesertim ex argento vivo. ${ }^{28}$
\end{abstract}

Pues desde hace unos veinte años se han empezado a ver menos pústulas, pero mayor número de gomas, mientras que sucedía al contrario en los primeros años: es decir, que las pústulas que se formaban (si es que aparecían algunas) eran más secas, y los dolores, si se daban, eran en cada caso más agudos. Pero sucede que con el paso de los años, más o menos en los últimos seis, se ha producido de nuevo un gran cambio en esta enfermedad. En efecto, ya se ven muy pocas pústulas y no hay casi ningún dolor

26 Lo seguía siendo a principios del siglo xx, antes de que el bacteriólogo alemán Paul Ehrlich descubriera, en 1910, el modo de acabar con la espiroqueta causante de la sífilis. En algunos carteles americanos de propaganda para evitar el contagio (los soldados americanos fueron los más afectados por esta enfermedad infecciosa durante la Primera Guerra Mundial) se podía leer la frase que aún suena en los tratados sobre la sífilis: "one night with Venus, a lifetime with Mercury."

27 Cf. John Henderson, "Fracastoro, il legno santo e la cura del 'mal francese'", en Alessandro Pastore e Enrico Peruzzi (eds.), Girolamo Fracastoro. Fra medicina, filosofia e scienze della natura. Atti del Convegno internazionale di studi in occasione del 450 anniversario della morte. Verona-Padova 9-11 ottobre 2003. Firenze, Leo S. Olschki, 2006, pp. 73-89, maxime 75-79.

28 Hieronymus Fracastorius, De contagione et contagiosis morbis et eorum curatione, libri III. Translation and notes by Wilmer Cave WrIGHT, Ph.D.. New York-London, G. P. Putnam's Sons, 1930, pp. 138-140. Hemos alterado las grafías ' $j$ ' por ' $i$ '. 
o este es muy leve; en cambio hay muchas gomas y, lo que a todos maravilla, la caída del cabello y de los restantes pelos torna a los hombres casi ridículos, llegándose a ver a unos sin barba, a otros sin cejas y a otros con la cabeza pelada, desgracia que antes se creía que derivaba de los tratamientos, especialmente del mercurio. ${ }^{29}$

Ante los graves daños que producía el mercurio en el organismo y los terribles padecimientos que tenían que soportar los que a tal cura se sometían, no es de admirar que la llegada de un nuevo producto que presuntamente curaba la enfermedad sin los dañinos efectos de la plata viva tuviese una aceptación prácticamente inmediata. El nuevo producto venía de las Indias occidentales; se trataba del guayaco, guayacán, palo santo o palo índico.

\section{EL GUAYACO}

Contrariamente a lo que sucedió con otros productos americanos, la difusión del guayaco fue inmediata. Se calcula, sin ninguna precisión, que su uso se extendió por España y Portugal entre 1506 y $1516^{30}$. Como bien indicaron Pardo Tomás y López Terrada ${ }^{31}$, ninguno de los investigadores que han estudiado la aparición del guayaco en el panorama médico del s. XVI y su difusión posterior parece haber dado importancia a esta ausencia de datos, lo que no deja de ser curioso, pues se trata de un asunto que merecería mayor atención. Los primeros textos de que disponemos ya indican que su uso es conocido, al menos en la península Ibérica, por lo que algunos de ellos no se explayan en una explicación que resultaría superflua al lector.

Tenemos noticia de que en 1516 o 1517 el obispo y canciller imperial de Maximiliano I Matthäus Lang, ya designado cardenal aunque aún no en posesión de su cargo, envió una comisión de médicos a Espańa y Portugal, con el objetivo de estudiar un nuevo producto de las Indias occidentales que estaba siendo empleado con bastante éxito contra el mal francés en los territorios peninsulares ${ }^{32}$. Es muy probable que, de entre los textos que tenemos, el más antiguo

29 Todas las traducciones que presentamos en el presente trabajo son de nuestra autoría.

30 Cf. Robert S. Munger, "Guaiacum, the Holy Wood of the New World", Journal of the History of Medicine and allied Sciences 4 (1949), pp. 196-229, maxime 197. Agradezco aquí la amabilidad de Jon Arrizabalaga, del CSIC de Barcelona, quien me hizo llegar copia de este artículo.

31 José PARDO TOMÁs y María Luz LóPEZ TERRADA, Las primeras noticias sobre plantas americanas en las relaciones de viajes y crónicas de Indias (1493-1553). Cuadernos valencianos de Historia de la medicina y de la ciencia XL. Serie A (monografías). Valencia, Instituto de Estudios Documentales e Históricos sobre la Ciencia, 1993, p. 222.

32 Cf. Munguer, "Guaiacum, the Holy Wood...", op. cit., p. 197; José María López PIÑero y María Luz López TERRADA, La influencia española en la introducción en Europa de las plantas americanas (1493-1623). Cuadernos valencianos de Historia de la medicina y de la ciencia LIII. Serie A (monografías). Valencia, Instituto de Estudios Documentales e Históricos sobre la Ciencia, 1997, p. 27. Disponible en http:// 
sea el del doctor Nikolaus Poll, físico imperial, (De cura morbi gallici per lignum guaiacum libellus), editado en 1535 pero escrito muy posiblemente en 1517. En su inicio nos da cuenta de la embajada de la que hemos hablado:

\begin{abstract}
Incipit modus curandi Alemanorum corpora morbo Gallico infecta cum ligno quodam Indico guycanum appellato secundum varias atque diversas receptarum descriptiones quas reverendissima et illustrissima Sua Dignitas ex diversis Hyspaniarum locis, ubi talem curam expertam habent, non parvis impensis neque sine magnatum ibidem favoribus singularibus ad nos usque etiam pro sua tuenda valitudine proferri procuravit, extractus per Nicolaum Pollucem, medicine professorem sacre Caesaris Maiestatis physicum. ${ }^{33}$
\end{abstract}

Comienza el modo de curar los cuerpos de los alemanes infectados por el mal francés por medio de cierto leño índico llamado guycano, según varias y diversas descripciones de recetas que Su Reverendísima e Ilustrísima Dignidad ha hecho que lleguen a nuestras manos, también para protección de su salud, procedentes de diversos lugares de las Españas donde tienen experiencia en tal remedio, con gastos no pequeños y no sin favores particulares de los grandes de allí, extraído por Nikolaus Poll, profesor de medicina y físico de la Sagrada Majestad del Emperador.

Aunque el texto de Nikolaus Poll haya sido probablemente el primero que se escribió de los que aún conservamos, la primera noticia publicada ${ }^{34}$ podría ser una receta titulada Eyn bewert Recept wie man das holtz Guagacan fur die kranckheyt Frantzosen brauchen sol etcetera. Se trata de un texto breve, pues la receta se indica en cinco páginas, especificando cómo se debe preparar y en qué momentos hay que beber la decocción de guayaco. Hubo dos ediciones, una en Ausburg y otra en Nuremnberg. En la de Nuremberg (Nürnberg, Hieronymus Höltzel, 1518), al principio del documento se indica la fecha de 24 de diciembre de $1518^{35}$, pero la de Ausburg es de 1 de diciembre, lo que hace a este texto anterior al que, el 17 de diciembre de ese mismo año, publicó el físico de Salzburgo Leonard Schmaus ${ }^{36}$, donde afirma que reunió diecinueve informes

digital.csic.es/bitstream/10261/88589/1/P_AMER_completo.pdf, accedido el 19-11-2013; PARDo TOMÁs y López TERRADA, Las primeras noticias..., op. cit., p. 221.

33 Max Harold FISCH and Dorothy May SCHuLLIAN, Nicolaus Pol doctor 1494: with a critical text of his guaiac tract. New York, Herbert Reichner for Cleveland Medical Library Association, 1947, p. 56.

34 Al menos, es la opinión de Munguer, "Guaiacum, the Holy Wood...", op. cit., p. 198 y de López PIÑERo y López TERrAda, La influencia española..., op. cit, p. 27.

35 La Biblioteca Digital de Múnich pone a disposición de los investigadores un ejemplar en la página http://daten.digitale-sammlungen.de/bsb00083987/image_1, en la que he realizado mis consultas.

36 Esta es la fecha que se indica al final del texto, donde después del fin, escrito en griego ( $\tau \varepsilon \lambda$ oo), se dice: In officina Sigismundi Grimm medicine doctoris atque Marci Wyrsung Auguste Vindelicorum anno etc. 
y estudios sobre el guayaco que le habían mandado algunos príncipes y señores de Alemania. En opinión de López Piñero y López Terrada ${ }^{37}$, Schamus confunde los territorios americanos con los territorios de las Indias orientales, error nada fuera de lo corriente en esta época, pues afirma haber recibido informes ex India et Portugalia. Nosotros no estamos tan seguros de ello, pues anteriormente dice de forma clara: de ligno quodam in occidentali India in insula Spagnola nouiter reperta. ${ }^{38}$ No sería imposible que lo que estuviese queriendo decir Schmaus es que los informes (y no el guayaco, que viene de las Indias occidentales) los recibieron desde Portugal y las Indias, y no desde España. Aunque este asunto merece mayor atención, puede ser que los primeros textos sobre el uso del guayaco hayan estado deliberadamente envueltos en un halo de misterio y sigilo para transmitir la idea de que se trataba de recetas secretas y de este modo potenciar su venta. Incluso antes de que los ricos banqueros Fugger controlasen gran parte del mercado de guayaco ${ }^{39}$, era de interés de mercaderes y de médicos conseguir que la preparación de este producto se hiciese según unas recetas médicas complejas, al estilo galénico de las medicinas tradicionales. En efecto, si se aceptase de modo natural que el guayaco producía una mejora del sufrimiento causado por el mal francés, o incluso su completa curación, como algunos afirmaban, mediante cualquier tipo de preparación, los médicos perderían buena parte de su credibilidad y de sus clientes, ya que cualquier particular podría comprar el producto y aplicárselo. Por otro lado, si los médicos publicasen y divulgasen la información de que el guayaco no producía ningún efecto práctico en los pacientes, los mercaderes podrían perder el lucrativo negocio que suponía la venta de un producto bastante caro, por su procedencia americana. Por lo tanto, era de interés común aceptar y hacer pública la información de que el guayaco funcionaba, pero solo si se consumía preparado de forma preceptiva, es decir, según el modo indicado por expertos médicos, al estilo de las complejas recetas para la preparación de otros productos medicinales. ${ }^{40}$

El espaldarazo definitivo al guayaco lo dio el humanista Ulrich von Hutten, con su obra De guaiaci medicina et morbo Gallico liber unus. ${ }^{41} \mathrm{Su}$ prestigio como humanista reconocido

MDXVIII, die vero XVII Decembris. Cf. Leonard Schmaus, Lucubratiuncula de morbo Gallico et cura eius nouiter reperta cum ligno Indico Leonardi Schmaus medicine professoris. Augsburg, Grimm \& Wirsung, 1518.

37 Op. cit., p. 27.

38 Schmaus, Lucubratiuncula, fol. $1 \mathrm{v}$.

39 Pero sin tener propiamente un monopolio, como muchas veces se ha dicho. Cf. Mark HäBERLEIN, The Fuggers of Augsburg. Pursuing Wealth and Honor in Renaissance Germany. Charlottesville \& London, University of Virginia Press, 2012 (= Die Fugger: Geschichte einer Augsburger Familie, 1367-1650. Stuttgart, W. Kohlhammer $\mathrm{GmbH}, 2006)$, p. 82, y la bibliografía allí citada en nota 23.

40 Cf. Jon Arrizabalaga, John Henderson \& Roger French, The Great Pox..., op. cit., p. 102.

41 La editio princeps fue publicada en Maguncia en abril de 1919. Así se dice en la anotación del editor al final del Libro: Maguntiae in Aedibus Joannis Scheffer Mense Aprili, Interregni vero Quarto. Anni M.D.xIX. Cum Privilegio Caesareo sexennii. Cf. F. F. A. POTTON, Livre du chevalier allemand Ulric de Hutten sur la maladie fançaise et sur les propriétés du bois de Gayac. Orné d'un portrait de l'auteur, précédé d'une notice 
y poeta laureado, junto a la elegancia de su latín, contribuyó enormemente al éxito de su opúsculo, que se difundió rápidamente. Hutten no era médico, sino alguien afectado por la enfermedad que hablaba de sus padecimientos en primera persona. Pero, al contrario de los médicos, él afirma que no se detendrá en cuestiones inútiles, diríamos nosotros que bizantinas, sobre el origen de la enfermedad; estas disquisiciones no llevan a ninguna parte. Su falta de esperanza en los remedios propuestos por los médicos venía de experiencia propia, pues estos experimentaron con él mezclando remedios exóticos y dándole muchos tratamientos que no sirvieron para nada. ${ }^{42}$

Hutten, en cambio, habla desde la posición de un hombre letrado con sentido común y que se ha visto personalmente afectado por este tormento. Y habla con el entusiasmo de quien se juzga curado por un nuevo fármaco milagroso. Su obra se vio pronto traducida a varias lenguas vulgares $^{43}$, especialmente alemán, inglés y francés, probablemente por influencia de la familia Fugger. Jacob Fugger, apodado El Rico, financió la coronación del emperador Carlos V en 1519, por lo que, en ese momento, era de suponer que las relaciones entre la familia de banqueros y la corona española se mantendrían durante varios años. A partir de 1521 los préstamos a esa corona serían muy elevados, cinco millones y medio de ducados entre esta fecha y 1555 , lo que representaba una quinta parte del total de los préstamos recibidos por Carlos $\mathrm{V}^{44}$. Como en ese mismo año de 1521 los Fugger abrieron su 'casa del leño's5 (se la solía llamar de ese modo, Holzhaus, porque el remedio administrado era esencialmente el leño santo o guayaco), podemos suponer que ya tenían el control del producto y por lo tanto el máximo interés en que se divulgase su uso.

A partir de entonces se dio una importante controversia entre los partidarios del guayaco y los del mercurio ${ }^{46}$, animada por los escritos de Paracelso, quien escribió ocho libros sobre el mal francés recomendando el uso del mercurio (mezclándolo con otros productos, pues no ignoraba su toxicidad) y condenando el del guayaco, por parecerle inútilil ${ }^{47}$. Naturalmente, incurrió en las iras de los Fugger y del decano de la facultad de medicina de Leipzig, Heinrich Stromer,

historique sur sa vie et ses ouvrages. Lyon, Imprimerie de Louis Perrin, 1865, p. xvi. Hemos manejado la edición citada en la nota 16, del mismo año.

42 [Medici] ausi tamen sunt exotica miscere nobis et multa quae minime oportuit inculcare. Ulrich von HUTTEN, De guaiaci medicina..., op. cit., fol. b (De causis morbi huius Caput II).

43 Se puede ver un estudio bibliográfico, interesante a pesar de su antigüedad, sobre la repercusión de esta y otras obras de Hutten, en Josef BENZING, Ulrich von Hutten und seine Drucker: eine Bibliographie der Schriften Huttens im 16. Jahrhundert, mit Beiträgen von Heinrich Grimm. Wiesbaden, Otto Harrassowitz, 1956. Hay otras obras más modernas, pero se centran más en el papel de Hutten en las controversias religiosas y en el triunfo de la reforma protestante en Alemania.

44 HÄBERLEIN, The Fuggers of Augsburg..., op. cit., p. 76.

45 HÄBERLEIN, The Fuggers of Augsburg..., op. cit., p. 82.

46 En este debate se centra el estudio de Mariano CIPRIANI, "Mercurio e mercurialisti, guaiaco e guaiacofili e "fenomeno Fugger"", Rivista di Storia della Medicina 6 (1962), pp. 87-113.

47 Cf. Jon Arrizabalaga, John Henderson \& Roger French, The Great Pox..., op. cit., p. 103. 
muy vinculado a esta familia y amigo de Hutten, a quien había ayudado con asesoramiento médico en la redacción de su obra sobre el guayaco.

En cualquier caso, la extensión del uso del guayaco fue imparable. Cuando Garcia de Orta parte para la India, en 1534, entre el equipaje debía cargar algo valioso con lo que poder comerciar a su llegada; decide entonces llevar cinco quintales de guayaco. ${ }^{48}$ En la colección de Luigi Luisini de 1566, gran parte de los autores seleccionados optan por aconsejar el leño santo, y este remedio es el que aparece en primer lugar en el frontispicio, cuando se hace mención de los remedios ${ }^{49}$. En fecha tan tardía como 1613 el hospital de S. Giacomo en Roma compraba 100 libras de carbón, 60 de leña para quemar y 5.000 de leño santo ${ }^{50}$. En términos generales, el consumo de guayaco para los hospitales de incurables era elevadísimo, y estos solían tener afluencia de enfermos que no estaban normalmente internados en los períodos en que administraban las curas de leño santo ${ }^{51}$.

\section{EL GUAYACO Y EL ÉBANO}

El movimiento humanista de finales del s. XV tenía como una de sus principales aspiraciones el desarrollo de la Historia Natural, es decir, la descripción de la naturaleza. Pero esta descripción estaba encuadrada en un objetivo más amplio de recuperación de los saberes clásicos. La firme creencia de que los autores griegos y latinos formaban un marco de referencia irreprensible para el estudio de cualquier materia y de que la principal tarea de cualquier estudioso era purgar los textos de la corrupción entrañada en ellos desde la Edad Media llevó a una especie de adoración de los clásicos, por lo menos de algunos autores. La creencia de que estos autores constituían un modelo que se debía seguir sin fisuras y un criterio incuestionable para evaluar el mundo se convirtió en una verdad asumida y no en una postura que debía ser defendida. Por el contrario, lo que hubo que defender en ocasiones era la posición contraria, es decir, los momentos de

48 Garcia de ORTA, Colóquios dos simples e drogas da Índia, ed. Conde de FICALHO, 2 vols.. Lisboa, Imprensa Nacional, 1985, vol. 2, p. 260 (Colóquio 47ㅇ): "Eu vim de Portugal hum anno antes, e trouxe pouca fazenda (como se acontece a muytos), entre a qual trouxe cinquo quintaes do páo chamado guaiacam." La cursiva es del texto.

49 Aloysius LuIsInUs, De morbo gallico..., op. cit. Comienza el título del frontispicio diciendo DE | MORBO GALLICO | OMNIA OVAE EXTANT | APVD OMNES MEDICOS | CVIVSCVNOVE NATIONIS, | Qui vel integris libris, vel quoquo alio modo huius affectus curationem | methodice aut empirice tradiderunt, diligenter hincinde conquisita, | sparsim inuenta, erroribus expurgata, \& in vnum | tandem hoc corpus redacta. | In quo de Ligno Indico, Salsa Perillia, Radice Chynae, Argento uiuo, I caeterisque rebus omnibus ad huius luis profligationem inuen- / tis, diffusissima tractatio habetur. La cursiva es del documento.

50 Cf. John Henderson, "Fracastoro, il legno santo...", op. cit., p. 86.

51 Cf. Jon Arrizabalaga, John Henderson \& Roger French, The Great Pox..., op. cit., pp. 145-233. 
desacuerdo con los textos clásicos ${ }^{52}$. La primera generación de humanistas médicos, la que va desde finales del siglo Xv hasta los años 30 del siglo XVI, se preocupó sobre todo de identificar las materias médicas que habían descrito los autores antiguos, de conciliar los textos de estos cuando mostraban discrepancias ${ }^{53}$ y de edificar una medicina que estuviese de acuerdo con las enseñanzas de esos autores, especialmente Galeno y Dioscórides, sin olvidar a Plinio.

Teniendo en cuenta esta actitud, no es de extrañar que la incorporación al saber botánico de las nuevas plantas, tanto orientales, llegadas a través del comercio portugués, como occidentales, transportadas desde las Indias occidentales por los españoles, se realizase de forma deficitaria. A principios del s. XVI, cuando se dio una importante proliferación de traducciones y comentarios a la obra de Dioscórides ${ }^{54}$, los comentaristas incluyeron pocas plantas nuevas en sus listas (una de las pocas excepciones era precisamente el guayaco, muy probablemente por las razones económicas apuntadas anteriormente) y, cuando lo hacían, normalmente incurrían en importantes errores. ${ }^{55}$ Claro está que tener que respetar el riguroso catálogo dioscorídeo, con una serie bien definida de plantas, minerales y animales que tratar y en un orden de igual modo muy bien determinado por la tradición ${ }^{56}$ y al mismo tiempo incluir nuevas especies no tratadas por ningún estudioso de la antigüedad era una tarea que exigía no poco esfuerzo y mucha audacia.

Cuando los humanistas quieren tratar esas realidades venidas de nuevas tierras, a oriente u occidente, necesitan describirlas. No podemos olvidar que la preocupación principal de la historia natural del Renacimiento es la descripción ${ }^{57}$. Pero, como es inevitable partir de los propios paradigmas conceptuales cuando damos de bruces con una realidad que no se deja encasillar fácilmente en nuestras categorías mentales, cuando los humanistas encontraban nuevas materias que describir, inevitablemente buscaban un parangón con la realidad europea, y especialmente mediterránea, que conocían. En una época en que la ilustración, es decir, el dibujo, aún no ha asumido un papel preponderante, aunque el público exija cada vez más su

52 Cf. Brian W. OLGILVIE, The Science of Describing. Natural History in Renaissance Europe. Chicago and London, The Universtity of Chicago Press, 2006, pp. 11-12.

53 Brian W. OLGILVIE, The Science of Describing..., op. cit., p. 29.

54 Para comprobarlo no hay más que echar un vistazo al tamaño del artículo de Riddle dedicado a Dioscórides dentro de la colección del Catalogus Translationum et Commentariorum. Cf. John M. RIDDLE, "Dioscorides", en F. Edward Cranz (ed.), Paul Oskar Kristeller (assoc. ed.), Catalogus Translationum et Commentariorum: Mediaeval and Renaissance Latin Translations and Commentaries. Annotated Lists and Guides, Vol. IV. Washington D. C., The Catholic University of America Press, 1980, pp. 1-144.

55 Cf. José María López PIÑERo, Medicina e historia natural en la sociedad española de los siglos XVI y xVII. Valencia, Universitat de València, 2007, p. 104.

56 Sobre el orden antiguo y el nuevo orden alfabético, probablemente realizado en el s. XI por Constantino el Africano, ver John M. RIDDLE, Dioscorides..., op. cit., p. 7.

57 Son palabras de Brian W. OLGILVIE, The Science of Describing..., op. cit., p. 6: "It is no exaggeration to say that description, as both process and result, is the central concern of Renaissance natural history." 
presencia y su importancia vaya en aumento ${ }^{58}$, lo primero al describir un objeto o un ser vivo insólito es decir a qué se parece. González Bueno recuerda que Hernán Cortés llamaba mezquitas a los templos náhualt. ${ }^{59}$ Este mismo autor, cuando analiza en otro trabajo la introducción de las plantas americanas en el comentario a Dioscórides más famoso del s. Xvi, el del italiano Pietro Andrea Mattioli, explica que las va incluyendo dentro de las entradas correspondientes a las plantas dioscorídeas, aproximándolas normalmente por alguna semejanza, y confundiéndolas en ocasiones. ${ }^{60}$ En realidad, Mattioli no hacía sino seguir una tradición que se fue poco a poco instituyendo, de modo que las materias nuevas tenían que introducirse en el lugar en que lo había hecho otro comentarista anterior, de lo contrario los lectores tendrían dificultad en encontrar la entrada correspondiente a lo que querían buscar. Ahora veremos este asunto en relación al guayaco que, como dice González Bueno, se hallaba en el tratado de Mattioli en la entrada del ébano.

Si bien es cierto que los comentaristas de Dioscórides introdujeron deficientemente, de forma general, otros productos diferentes a los transmitidos por la tradición libresca, el hecho de que el caso de Amato Lusitano era algo diferente ya fue visto por el siempre perspicaz López Piñero, quien indica que el autor albicastrense supo incluir noticias de primera mano debido

58 Sobre la relevancia de las imágenes en los tratados médicos y botánicos, véase Sachiko Kusukawa, Picturing the Book of Nature. Image, Text, and Argument in Sixteenth-Century Human Anatomy and Medical Botany. Chicago, University of Chicago Press, 2012, y el artículo de Carlos de Jesus, "Amato Lusitano e a importância da ilustração botânica no século xvI. Em torno das edições lionesas das Enarrationes (1558)", en este mismo volumen.

59 Antonio González Bueno, "La flora del paraíso: recepción de las plantas americanas en la literatura científica europea del Renacimiento" en Alfredo BARATAS (ed.), Memorias de la Real Sociedad Española de Historia Natural. Tomo III. $2^{a}$ época. El libro de la Naturaleza. Madrid, Facultades de Biología y Geología - Ciudad Universitaria, 2004, pp. 5-33, maxime 10. También Oviedo compara las cabañas del poblado Thamara con mezquitas, diciendo: "Allí se halló un buhío á manera de mezquita ó casa de oraçion desta gente". Gonzalo FERNÁNDEZ DE OVIEDO, Historia general y natural de las Indias, islas y Tierra-Firme del mar Océano, editada por D. José Amador de los Ríos para la Real Academia de la Historia. Tomo primero de la segunda parte. Madrid, Imprenta de la Real Academia de la Historia, 1852, p. 277.

60 Antonio González Bueno, "El Descubrimiento de la Naturaleza del Nuevo Mundo: Las Plantas Americanas en la Europa del siglo XvI", Circumscribere. International Journal for the History of Science 2 (2007), pp. 10-25, http://revistas.pucsp.br/index.php/circumhc/article/view/569/1028, p. 18. Merece la pena transcribir el fragmento: "el guayaco pasa, sin apenas precisión, como una suerte de ébano pero al que se le reconocen virtudes antisifilíticas y sudoríferas, como a la zarzaparrilla americana, que es claramente identificada con la mediterránea, siguiendo la opinión que, años atrás, hubiera defendido Luca Ghini, profesor de la Universidad de Padua; un "piper in India nasci...", de pequeños frutos en forma de cuernos, figura junto a la pimienta y el clavo. Apenas dos líneas merecen los tomates, denominados "pomi d'oro" o "mala aurea", de frutos dorados y rojos, aproximados en éste, y confundidos en otros textos renacentistas, con las berenjenas. Algo más añade sobre unas calabazas de Indias, conocidas en la península italiana desde algún tiempo atrás, cultivadas sobre semillas de procedencia americana y de las que señala la ventaja de poder ser conservadas durante todo el invierno. También tienen su sitio los "claveles de Indias", rápidamente extendidos por los jardines europeos; y por supuesto el maíz, planta ya bien conocido en estos años centrales del siglo xvı." 
a su conocimiento de las plantas de la península Ibérica y de algunos productos ultramarinos, venidos de las Indias orientales y de América. ${ }^{61}$ António Andrade demostró recientemente que los conocimientos que João Rodrigues de Castelo Branco (más tarde conocido tan solo como Amato Lusitano) poseía sobre los productos orientales le venían no solo de su actividad como médico y de su mirada atenta, sino de los negocios familiares en los que se involucró cuando salió de Portugal rumbo a Amberes en 1534, pues formaba parte de la familia de mercaderes judíos Pires-Cohen, sobrino como era de Henrique Pires, elemento nuclear de una de las redes familiares extendidas por toda Europa dedicadas al comercio. ${ }^{62}$

Amato Lusitano publicó el primero de sus comentarios a Dioscórides, el Index Dioscoridis, ${ }^{63}$ dos años después de su llegada a Amberes. Era obra de juventud, pues el autor contaba tan solo con 25 años de edad, y por ello con bastante errores, no solo tipográficos, como el propio autor denuncia en su prólogo al lector, lo que casi lo lleva, según sus palabras, a detener su publicación, sino incluso algunos fruto de una mala comprensión de los textos de que se sirvió. Muy diferente es su comentario a Dioscórides publicado en la madurez, a los 42 años de edad, las Enarrationes. ${ }^{64}$ Ahí hace gala de la originalidad que López Piñero apunta en su revisión de los comentaristas de Dioscórides. Sin embargo, en este trabajo nos vamos a detener en su primera obra, de la que espero sacar algunas conclusiones interesantes. Dejaremos para un estudio posterior la curiosa evolución experimentada entre la publicación de una obra y la de la otra.

Cuando se habla de esta obra, no se tiene en consideración, o al menos no se da importancia al hecho de que la entrada del ébano es, con un amplio margen, la más extensa de los dos libros de Dioscórides que incluye. Bastante más extensa que, por ejemplo, la primera entrada, sobre el iris, sobredimensionada porque el autor la usa para realizar una presentación del libro y dirigirse a los lectores, dejando de hecho un espacio cuando va a empezar a hablar propiamente de la planta que le ocupa. ${ }^{65}$ La del ébano comienza en la página $23 \mathrm{v}$ y acaba en la $26 \mathrm{r}$, con texto corrido, algo curioso si tenemos en cuenta que algunas páginas contienen hasta cinco entradas. Evidentemente, el motivo de esta extensión fuera de lo común para un producto que no merece la misma atención en el texto del autor griego radica en que, en realidad, la entrada

61 José María López PIÑEro, Medicina e historia natural..., op. cit., p. 98.

62 António Manuel Lopes Andrade, "Ciência, Negócio e Religião: Amato Lusitano em Antuérpia", en Inês de Ornellas CASTRO e Vanda AnASTÁcio (coord.), Revisitar os Saberes - Referências Clássicas na Cultura Portuguesa do Renascimento à Época Moderna. Lisboa, Centro de Estudos Clássicos - Faculdade de Letras da Universidade de Lisboa, 2010, pp. 9-49.

63 Amatus Lusitanus (João Rodrigues de Castelo Branco), Index Dioscoridis. Antuerpiae, excudebat Vidua Martini Caesaris, 1536.

64 AmATUS LUSITANUS, In Dioscoridis Anazarbei de medica materia libros quinque enarrationes eruditissimae. Venetiis, apud Gualterum Scotum, 1553. Para conocer las vicisitudes de las diferentes ediciones de los textos de Amato Lusitano, ver João José Alves DIAS, Amato Lusitano e a sua obra: séculos XVI exVII. Lisboa, Biblioteca Nacional de Portugal, 2011.

65 Amatus Lusitanus, Index Dioscoridis..., op. cit., p. 2 r. 
se aprovecha para hablar del guayaco. O, mejor dicho, João Rodrigues trata del ébano, que identifica plenamente con el leño santo.

Al tratar los nombres que recibió el guayaco, Munger afirma que, al principio, unos pocos escritores lo identificaban con el ébano. ${ }^{66}$ Uno de ellos fue Amato Lusitano, y con mucha mayor rotundidad en el Index, de fecha tan temprana como 1536. Las cuestiones que se nos plantean son: ¿cómo se produjo esa identificación?, ¿en quién se fijó Amato para relacionar ambos productos?, ¿qué papel juega el texto de Amato en el debate sobre el guayaco y el ébano?

En 1550 se publica en Lyon una edición de la traducción de Dioscórides de Jean Ruel (la editio princeps es de 1516, publicada en París) con comentarios añadidos, de la autoría de H. B. M. En su exhaustiva obra, Riddle, basándose en la identificación del estudioso DuPetitThouars, indica que estas iniciales se refieren posiblemente a Johannes Bruyerinus. Ignoramos si esta atribución de autoría ha sido rebatida por alguien. Sin haber comprobado su fiabilidad, hemos visto que una notación manuscrita del ejemplar de la Biblioteca Complutense indica que el autor es Huberto Barlando, médico belga que fue profesor en Lovaina. En esta obra, al final de la traducción de Ruel en la entrada del ébano, se incluye un pequeño comentario en el que se dice: Quidam guayacum ebeni speciem putant; istud nec affirmare nec negare ausim, cum a nullo veterum scriptorum praedictum sit qualia folia, flores et fructus ebenus producat. ${ }^{67}$ Podemos deducir de aquí dos cosas: que ya era común, aunque no todo el mundo lo compartía, pensar que el guayaco fuese una especie de ébano, y que este último producto ya era menos conocido que el americano, pues el autor del comentario no se atreve a manifestar su opinión por la ausencia de descripciones de las hojas, flores y fruto del ébano. Una década antes los comentaristas se quejaban de no conocer las del guayaco, porque no se enviaban desde las Indias occidentales, ya que solo interesaba el lucro de la madera (solo esta se usaba para el tratamiento del mal francés) y no el conocimiento científico.

Pero si el autor incluye esta duda en su comentario al ébano es porque otros comentaristas de Dioscórides ya lo están haciendo. En efecto, las mismas dudas vemos ya en los comentarios de Pietro Andrea Mattioli y Andrés Laguna. Mattioli introduce la siguiente consideración en su comentario al ébano:

\footnotetext{
Sunt qui lignum ex Indijs petitum, quod quidam GVAIACVM, nonnulli Guaiacanum, plerique uero Lignum sanctum appellant, cuius aduersus Gallicam luem praecipus est usus, ebeni genus esse crediderint. Quod quidem nec asserere nec negari ausim: quandoquidem
}

66 Munguer, "Guaiacum, the Holy Wood...", op. cit., p. 204.

67 [Hubertus Barlandus], Pedanii Dioscoridis Anarzabei de medicinali materia libri sex, loanne Ruellio Suessionensi interprete, cuilibet capiti additae annotationes, eruditae et compendiariae e selectiori medicorum promptuario. Lugduni, Apud Balthazarem Arnolletum, 1550, p. 105 
nusquam inuenerim apud quenquam tum ueterum, tum recentiorum scriptorum, quas frondes, quos flores, quosque fructus proferat ebenus. ${ }^{68}$

Hay quienes piensan que el leño que se trae de las Indias, que unos llaman guayaco, algunos guayacano, pero que la mayoría conoce como leño santo, y sobre todo se emplea contra la peste francesa, pertenece a la especie del ébano. Esto no me atrevería yo a afirmarlo ni a negarlo, ya que nunca he encontrado en ningún autor, ni entre los antiguos ni entre los modernos, qué hojas, flores y frutos da el ébano.

Parece clara la influencia del texto de Mattioli en Barlando. Como vemos, el humanista sienense tampoco quiere afirmar la identidad entre uno y otro. A continuación de este fragmento, Mattioli comenta pormenorizadamente las formas de preparación del guayaco, ya que era una materia de clarísimo interés para sus lectores. ${ }^{69}$

En cuanto a Andrés Laguna, ${ }^{70}$ en su comentario latino de 1554 nada dice sobre el guayaco cuando corrige algunos errores de la traducción de Ruel. ${ }^{71}$ En cambio, lo trata con profundidad en su traducción comentada de Dioscórides al español, publicada un año después. Su opinión, menos prudente que la de Mattioli, abraza sin miedo la teoría de que el guayaco es una especie de ébano:

Hallanse muchas especies del Ebano, entre las quales es una, y la mas excellente, aquel bendito y sancto madero, llamado vulgarmente Guayaco, el qual por la diuina bondad y misericordia fue communicado à los hombres. ${ }^{72}$

68 Pietro Andrea MAttıolı, Commentarii in libros sex Pedacii Dioscoridis Anazarbei de medica materia. Adiectis quam plurimis plantarum et animalium imaginibus, eodem authore. Venetiis, in officina Erasmiana, apud Vincentiu Valgrisium, 1554, p. 107

69 Mattioli ya había escrito un Morbi Gallici novum ac utilissimum opusculum, publicado en 1534 (o 1530, fecha que ha sido propuesta por algunos investigadores), que fue reeditado al año siguiente en el Liber de morbo Gallico in quo diversi celeberrimi in tale materia scribentes medicine continentur auctores. Veneza, [Giovanni Padovano \& Venturino Ruffinelli], 1535. Tras consultar esta edición, no he encontrado niguna relación con el ébano en las pocas ocasiones que Mattioli habla del guayaco.

70 Para un cabal conocimiento de las características de la obra del humanista segoviano, resulta esencial la obra de Miguel Ángel González MANJARRÉs, Andrés Laguna y el Humanismo médico. Salamanca, Junta de Castilla y León, 2000.

71 Andrés LAGUNA, Annotationes in Dioscoridem Anazarbeum, per Andream Lacunam Segobiensem Medicum Iulii III Pont[tificis] Max[imi] iuxta vetustissimorum codicum fidem elaboratae. Lugduni, Apud Gulielmum Rouillium, 1554, pp. 46-47.

72 Andrés LAgUna, Pedacio Dioscorides Anazarbeo, acerca de la materia medicinal y de los venenos mortíferos. Anvers, Casa de Juan Latino, 1555, p. 81. 
A lo cual sigue una serie de alabanzas ensalzando las virtudes de este leño milagroso y una pormenorizada descripción de su preparación, como se veía en Mattioli.

Tanto la obra de Mattioli como la de Laguna son bastante posteriores al Index de Amato, por lo que no nos sirven para resolver las cuestiones que planteábamos.

Intentaremos ahora atar los cabos que hemos ido dejando sueltos en nuestro razonamiento, para procurar comprender cómo se introdujo el guayaco en el espacio del ébano.

Decíamos antes que cuando los humanistas encontraban nuevas materias que describir, inevitablemente buscaban un parangón con la realidad europea y especialmente mediterránea que conocían o, aún mejor, con la cultura libresca de los clásicos, verdadero modelo donde se debe encajar la nueva realidad. En la que podría ser la primera descripción del guayaco escrita (no se llega a decir el nombre de la madera) ya se menciona al ébano, aunque sea de forma más o menos indirecta. Nos referimos a un texto del libro quinto de la primera década de las $D e$ orbe nouo decades de Pedro Mártir de Anglería. Debe de haber sido escrito bastante pronto, pues se calcula que Anglería empezó a escribir esa primera década hacia 1493, habiéndola finalizado en $1510 .^{73}$ Puesto que las tres primeras décadas fueron publicadas en 1516, es natural que lo que cuenta Anglería sobre cierta madera fuese conocido antes de la publicación conjunta de las ocho décadas, en 1526. Mucho más si tenemos en cuenta que gran parte de los textos de Anglería circulaban manuscritos antes de su publicación, o incluso en traducciones no autorizadas por él, como el opúsculo Libretto de tutta la navigatione de' re de Spagna de le isole et terreni nuovamente trovati, traducción al italiano de la primera década (que no coincide con la que posteriormente sería la primera, pues Anglería reunió dos décadas en una), realizada por Angelo Trivigiano y publicada mucho antes que el original latino ${ }^{74}$. El texto en cuestión al que nos referimos es el siguiente:

\footnotetext{
Itinere autem medio, in uico quod est ipsius regiae sororis gazophylacium pernoctatum est. Illius uero thesauri non aurum, non argentum, non gemmae, sed utensilia tantum resque ad humanum usum attinentia, utputa sedilia, paropsides, lances, pelues, patellae ex ligno nigerrimo, lubrico, lucido (quod hebenum eximius artium et medicinae doctor tuus Ioannes Baptista Elisius esse contendit) confectae et arte mira laboratae. ${ }^{75}$
}

73 Cf. José Torre Revello, "Pedro Mártir de Anglería y su obra De orbe nouo", Thesaurus: boletín del Instituto Caro y Cuervo 12 (1-3), pp. 133-153, maxime 150.

74 Cf. José Pardo Tomás y María Luz López Terrada, Las primeras noticias..., op. cit., p. 50.

75 La cita está tomada de Petri MARTYRIS AB ANGLERIA Mediolanensis oratoris clarissimi Ferdinandi et Helisabeth Hispaniarum quondam regum a consiliis de rebus Oceanicis et Orbe nouo decades tres (=Petrus MARTYR AB ANGLerIA, De rebus Oceanicis et Orbe nouo decades tres). Basileae, apud loannem Bebelium, 1533, p. 14 r. 
Pero se pernoctó a mitad de camino, en un poblado que es una sala de tesoro de la propia hermana regia. Pero no era oro, ni plata ni piedras preciosas lo que formaban aquel tesoro, sino tan solo utensilios y enseres de uso corriente, como por ejemplo sillas, bandejas, platos, vasijas, ensaladeras hechas de un leño negrísimo, pulido, brillante (que tu doctor en medicina y eximio cultivador de las artes Juan Bautista Elisio defiende que es ébano) y talladas con admirable industria.

Por lo tanto, teniendo en cuenta lo que hemos dicho sobre la difusión de la obra de Anglería, desde los primeros tiempos, antes de conocerse el nombre del producto descrito, los eruditos ya podían saber que había quien sostuviese la opinión de que era ébano.

Al mismo tiempo, como vimos, en los primeros tiempos tras la aparición del mal francés el debate se estableció sobre si la enfermedad era nueva o no; de los que pensaban que era nueva, algunos aceptaban que se hubiera producido espontáneamente en Europa por diversos motivos, entre los que no estaba excluido el castigo divino o la confluencia astral; otros, los menos, buscaban un origen externo, en África o Asia. La teoría del origen americano del mal francés apareció tardíamente en relación al surgimiento de la enfermedad. Es opinión de Munger ${ }^{76}$ y Cipriani ${ }^{77}$, que nosotros compartimos, que esta teoría solo ganó fuerza cuando interesaba vender el guayaco, y esto porque la teoría natural del Renacimiento era que de donde viene el mal, viene la curación. Es decir, si Dios permite, para castigar a los hombres, que surja determinada enfermedad en una zona del mundo, para compensar y premiar el esfuerzo de los hombres les concede que el medio para sanar se encuentre en el mismo sitio. Cuando el negocio del guayaco se estaba haciendo lucrativo, la convicción de que el mal francés provenía de las islas donde se producía el guayaco era un modo de reforzar su consumo. Ya en 1519, Hutten, una de las fuentes de Amato -como el propio João Rodrigues nos dice al final de la entrada del ébano y se torna evidente ante el mínimo cotejo de los textos-, había dicho que los indígenas de la isla Española padecían el mal francés de forma endémica como los europeos la viruela ${ }^{78}$, aunque esto no significase, ni se pudiese interpretar que hubiera surgido allí. Más bien al contrario, la descripción de Hutten parece sugerir que la enfermedad es diferente, no solo 'con la misma frecuencia que la viruela' sino también 'tan inconsecuente como la viruela' (en comparación con la enfermedad mortal del mal francés en Europa). Además, una prueba fehaciente de que reconocer la antigüedad de la dolencia en las Indias occidentales y pensar que el origen de este mal provenía de allí eran dos cosas distintas nos la da Schmaus quien, un año antes que Hutten, ya había indicado esa antigüedad ${ }^{79}$ para, acto

76 Munguer, "Guaiacum, the Holy Wood...", op. cit..

77 Mariano CIPRIANI, "Mercurio e mercurialisti...", op. cit..

78 Ulrich von HUtTEn, De guaiaci medicina..., op. cit., fol. biii (Guaiaci descriptio et eius inuentio ac nomen Caput VI): Ipsius Insule omnes morbo Gallico aliquando laborant accolae, quemadmodum variolis nos.

79 Leonard SchmaUs, Lucubratiuncula ... op. cit., p. aii v.: quippe compertum est iam omnibus occidentales 
seguido, exponer una larga lista de conjeturas sobre el surgimiento de la enfermedad sin que se le ocurriese la posibilidad de que viniera del continente americano.

Cuando aparecen ya referencias específicas en los textos sobre el supuesto origen americano es en 1526, en el Sumario de la natural historia de las Indias que publicó en Toledo el cronista Gonzalo Fernández de Oviedo. El capítulo 75 está dedicado al palo santo y en él se dan unas informaciones interesantes, sobre todo cuando se comparan con las que el propio Fernández de Oviedo da en otra obra posterior, la Historia general y natural de las Indias, de 1535. En el Sumario describe el palo santo o guayacán, como lo llaman los indígenas. Se detiene algo más en la descripción de aquellas partes que no se conocen en Europa, es decir, de todo lo que no es el tronco, y explica cómo lo toman los nativos, alertando de que en las Indias, por el hecho de tomar el producto recién cogido y por estar situados en una zona de diferente temperatura que España, la forma de preparación y administración no será igual, y por eso sus lectores no deben guiarse por sus explicaciones. Vemos aquí el cuidado de no entrometerse en terreno de médicos con una receta excesivamente sencilla por comparación a las recetas de los doctores en medicina. Pero una parte bastante relevante es la que se refiere al origen del mal francés:

\footnotetext{
"Puede V. Magestad tener por cierto que aquesta enfermedad vino de las Indias y es muy comun a los Indios, pero no peligrosa tanto en aquellas partes como en estas, antes muy facilmente los indios se curan en las yslas con este palo y en tierra firme con otras yeruas o cosas que ellos saben porque son muy grandes eruolarios. La primera vez que aquesta enfermedad en España se vido fue despues quel Almirante don Christoual Colom descubrio las Indias y torno a estas partes, y algunos christianos de los que con el vinieron que se hallaron en aquel descubrimiento, y los que el segundo viaje hizieron, que fueron mas, truxeron esta plaga y dellos se pego a otras personas. Y despues, el año de mil y quatro cientos y nouenta y cinco, que el gran capitan don Gonçalo Fernandez de Cordoua passo a Ytalia con gente en fauor del rey don Fernando, jouen de Napoles, contra el Rey Charles de Françia, el de la cabeça gruessa, por mandado de los Catholicos reyes don Fernando y dońa Ysabel de inmortal memoria, abuelos de V. S. M. passo esta enfermedad con algunos de aquellos Españoles y fue la primera vez que en Ytalia se uido y como era en la sazon que los Franceses passaron con el dicho rey Charlo, llamaron a este mal los ytalianos, el mal frances, y los françeses le llaman el mal de Napoles porque tan poco le auían visto ellos hasta aquella guerra. Y de ay se desparzio por toda la christiandad." ${ }^{80}$
}

Indos per plurimos annos hoc morbo grauiter laborasse, medicinamque qua semper usi sunt contra hunc morbum nostris mercatoribus iam indicarunt.

80 Gonzalo Fernández de Oviedo, Sumario de la natural y general historia de las Indias. Toledo, Ramón de Petrás, 1526, pp. 38r-38v. 
Se trata, probablemente, de un momento importante para el comercio del guayaco. Se está vendiendo a buen ritmo, como indican las cifras que dimos anteriormente, pero existen voces críticas: en esa fecha Paracelso se establece en Basilea, y muchos estudiantes están dispuestos a seguir sus opiniones mercuriales. Además, la muerte de Hutten por el mal francés, pocos años antes (1523), a despecho de su exultante regocijo por haber hallado la cura milagrosa, suponía un revés para los defensores del guayaco como remedio sobre el mercurio. Conviene, así pues, insistir en la idea de que la cura por guayaco se produce en el mismo sitio del que proviene la enfermedad. ${ }^{81}$

Cuando Gonález de Oviedo retoma el asunto en su Historia general y natural de las Indias, publicada en 1535, aunque escrita antes y con una divulgación inmediata, insiste de forma aún más clara y contundente en el origen americano de la enfermedad e introduce una nueva cuestión: lo que se llama palo santo o guayaco está compuesto en realidad por dos especies, que él propone diferenciar usando un nombre para cada una (se trata de Guaiacum officinale L. y Guaiacum sanctum L.):

Dos árboles hay muy notables y exçelentes en estas islae é aun en la Tierra-Firme; porque assi como es comun el mal de las buas en todas estas partes, quiere la misericordia divina que assi sea el remedio comunicado, é se halle para curar esta dolençia. Pero aunque en otras partes se halle esta enfermedad, el origen donde los chripstianos vieron las buas, y experimentaron é vieron curarlas y experimentar el árbol del guayacan fué en esta Ista Española. El otro se llama palo sancto, y este hay en la isla de Boriquen, llamada agora por los españoles Sanct Johan; é quando della se hable, se dirá del palo sancto. ${ }^{82}$

La divulgación de las obras de Mártir de Anglería, Francisco Delicado y Fernández de Oviedo por la Italia de los humanistas fue inmediata y extensa, como demuestra Pardo Tomás ${ }^{83}$ y también López Piñero y López Terrada ${ }^{84}$, no solo por medio de traducciones y ediciones,

81 Es probable que la mejoría que experimentaban los que tomaban guayaco se debiese esencialmente al abandono de las nocivas curas mercuriales, aunque también podía contribuir a ello el riguroso régimen de vida que acompañaba a la receta del tratamiento por leño santo.

82 Gonzalo Fernández de OVIedo, Historia general y natural de las Indias, islas y Tierra-Firme del mar Océano, editada por D. José Amador de los Ríos para la Real Academia de la Historia. Primera parte. Madrid, Imprenta de la Real Academia de la Historia, 1851, p. 363.

83 José PARDo TOMÁs, "Obras españolas sobre historia natural y materia médica americanas en la Italia del siglo xvı", Asclepio 43.1 (1991), pp. 51-94, maxime 52-53. Allí explica como el famoso humanista Andrea Navagero, que era embajador veneciano en Toledo, volvió a Venecia en 1528 con, entre otras obras, un ejemplar del Sumario de Oviedo.

84 José María López Piñero y María Luz López TerRadA, La influencia española..., op. cit., pp. 19-22. Destaca especialmente las relaciones que mantuvieron los humanistas Pietro Bembo y Girolamo Fracastoro con los autores españoles a través de Navagero. 
sino por las relaciones personales entre eruditos que intercambiaban correo. Podemos asumir, así pues, que las informaciones pasaron inmediatamente a las obras de autores italianos, sobre todo aquellas que se relacionaban con un tema tan candente como eran los remedios para el mal francés. Por lo tanto, las informaciones sobre el guayaco se extenderían rápidamente por toda Europa a través de los autores italianos cuando no lo hicieron directamente por la lectura de los textos publicados en España. ${ }^{85}$

\title{
5. ¿EL GUAYACO ES ÉBANO?
}

Pero no creemos que fuera directamente Oviedo quien puso en comparación el guayaco y el ébano. Afirma Munger ${ }^{86}$ que el cronista, en su Historia Natural de 1530, dice que algunos prefieren llamar ébano al guayaco. Como no indica dónde lo dice, hemos buscado esta afirmación de Oviedo, pero en vano. La única referencia que hemos encontrado que pudiera hacer pensar en esta identificación es la siguiente, cuando habla del pueblo de Thamara en el capítulo 2 del libro 25 :

\begin{abstract}
Los veçinos deste pueblo por la mayor parte labran oro, é tienen sus forjas é yunques é martillos, que son de piedras fuertes: algunos dicen que son de un metal negro á manera de esmeril. Los martillos son tamaños como huevos ó mas pequeños, é los yunques tan grandes, como un quesso mallorquin, de otras piedras fortíssimas: los fuelles son unos canutos tan gruessos como tres dedos ó mas, y tan luengos como dos palmos. Tienen unas romanas sotiles con que pessan, y son de un hueso blanco, que quiere paresçer marfil; y tambien las hay de un palo negro, como ébano. ${ }^{87}$
\end{abstract}

Si fuera este el fragmento a que hace referencia Munger, sería demasiado aventurado pensar que el cronista está designando el guayaco, dado que en el capítulo en que trata específicamente este árbol, cuyo inicio hemos transcrito más arriba en este trabajo, lo llama siempre guayacán o palo santo. No tendría por qué decir 'un palo negro'.

Pero, sin duda, las noticias de Pedro Mártir y de Fernández de Oviedo allanaban el camino para la comparación o identificación del guayaco y el ébano.

85 Amato Lusitano podría haber manejado los textos de Oviedo, a juzgar por unos comentarios sobre el plátano que trataremos en otro lugar.

86 Op. cit., p. 204.

87 Gonzalo Fernández de Oviedo, Historia general....Tomo primero de la segunda parte, op. cit., p. 274. La cursiva es nuestra. 
Vamos a intentar rastrear esta comparación en los textos que conservamos, sin pretensiones de exhaustividad, ni mucho menos, pero fijándonos en algunos hitos importantes bien de la botánica en general bien de los tratamientos contra el mal francés en particular, hasta llegar al Index de Amato Lusitano, para responder a las preguntas que planteábamos más arriba.

Nada sobre el guayaco encontramos en el Corolario de Hermolao Bárbaro editado por Egnacio $^{88}$. Aunque era de esperar, considerando la fecha en que fue compuesto y publicado, intentamos leer entre líneas la entrada del ébano, teniendo en cuenta las palabras de Amato: Nobis hac de re Hermolaus Barbarus astipulatur, si quis nucleum non tantum verborum corticem spectet. ${ }^{89}$ Sin embargo, la única coincidencia se halla en las propiedades curativas que se atribuyen al ébano, semejantes en ambos autores.

Tampoco encontramos nada en la obra de Benedicto Textor, publicada en París dos ańos antes que la de Amato. ${ }^{90}$ Esta obra es muy interesante porque se aparta de los comentarios dioscorídeos al uso, dividiendo las plantas de una forma muy práctica, con lo que respeta lo prometido en el título, guiándose más por la experiencia que por la tradición. Comienza con una moderna tabla de definiciones para el vocabulario que va a utilizar y agrupa las plantas según semejanzas y diferencias a partir de diversas propiedades cuantitativas y cualitativas, tiempo de maduración, sustancia, utilización, etc. A pesar de esto, no parece haber tenido interés en hablar del ébano y mucho menos del guayaco.

Creemos que una de las primeras comparaciones explícitas entre estos dos productos que se pueden leer en los textos humanistas (dejando aparte el comentario de Mártir de Anglería, escrito, como dije, antes de especificar el nombre de la madera americana) es la de Fracastoro en su poema Syphilis. Como hemos dicho más arriba, este médico, poeta y poetólogo tenía un buen conocimiento de las plantas americanas por los contactos con las publicaciones y los autores hispanos a través de su amigo y también miembro del círculo veneciano Andreas Navagero. No le faltaba, por tanto, material con que escribir su poema sobre el mal francés, que él denominó artísticamente sífilis. Este poema en hexámetros, a medio camino entre la poesía épica y la didáctica, se compone de tres libros de algo más de 400 versos cada uno. Tras acabar el segundo libro con una desagradable visión de los sacrificios que hay que soportar al someterse a las diferentes curas contra la sífilis, empieza el tercero de forma exultante, cantando como un don de los propios dioses - pues la obra, como es normal en la épica del

88 Ioannis Baptistæ EGNATII, In Dioscoridem ab Hermolao Barbaro tralatum annotamenta. [Venetiis], Aloisius \& Franciscus Barbari \& loannes Bartholomaeus Astensis, [1516], maxime XVIIIV. Es una edición catalogada como dudosa por Riddle. Cf. John M. RIDDLE, Dioscorides..., op. cit., p. 16.

89 Amatus Lusitanus, Index Dioscoridis..., op. cit., p. 24r: "En este asunto Hermolao Bárbaro coincide con nosotros, si se mira al meollo de sus palabras y no solo a lo externo."

90 Hemos manejado la editio princeps, Benedictus Textor, Stirpium differentiae ex Dioscoride secundum locos communes. Opus ad ipsarum plantarum cognitionem admodum conducibile. Parisiis, Apud Simonem Colinaeum, 1534. 
Renacimiento, se reviste de un manto de mitología pagana que el fervor religioso de la época acepta por su halo de simbolismo- la llegada del palo santo (Hyacum, v. 35). Inmediatamente, llega su descripción, donde podemos leer:
Materia indomita est, duro et pene aemula ferro
robora, quae resinam sudant incensa tenacem.
Dissectae color haud simplex. In cortice, lauri
exteriore uiret leuor, pars altera pallet
buxea, at interior nigro suffusca colore est,
iuglandem ebenumque inter. Quod si inde ruberet,
iam poterat uarijs aequare coloribus Irim. ${ }^{91}$
Es su madera indomable, casi igual su reciedumbre
que el hierro duro y transpira tenaz resina a la lumbre.
El color, al corte, es doble. En la corteza verdea
un bruñido de laurel. La otra parte se blanquea
como boj. Mas su interior morenamente negrea
entre el ébano y nogal. Si también enrojeciera,
por sus variados colores igualar a Iris pudiera.

Un año más tarde edita Otto Brunfels su Noui herbarii en Estrasburgo. Aunque se trata de una obra que sigue la lista de Dioscórides sin una exégesis tan exhaustiva como será la de los comentaristas posteriores como Amato, Mattioli o Laguna, destaca su preocupación por la correcta identificación de las plantas. La entrada del ébano, como muchas otras, no aparece en el corpus principal de la obra, sino en el De uera herbarum cognitione appendix, que reinicia la numeración, y dice lo siguiente:

Hebaenus: iuxta omnia signa et notas quibus hanc describunt Hermolaus Barbarus et Plinius apparet quiddam habere nostro Guaiaco simile, aut certe eius genere esse; sed non habeo cur id certo affirmem. ${ }^{92}$

91 Fracastoro, Syphilis, 3.40-46. Cf. Jerôme Fracastor, La syphilis ou le mal français..., op. cit., p. 63.

92 Otto Brunfels, Noui Herbarii Tomus II, per Oth[o] Brunf[elsio] recens editus. Argentorati, Apud loannem Scottum, 1531, p. 8 (tras comenzar una nueva numeración en el appendix). En la edición de 1536 realizada también en Estrasburgo y en misma casa editorial de Juan Escoto, el texto, idéntico, aparece en la página 102. 
ÉBANO: A juzgar por todos los signos y características con que lo describen Hermolao Bárbaro y Plinio, parece tener algo semejante a nuestro guayaco, o sin duda es de su mismo género, pero no tengo cómo afirmar esto de forma segura.

Como vemos, Brunfels ha ido un paso más allá de Fracastoro pues, aparte de constatar el parecido, ya plantea la posibilidad, bastante firme aunque no con rotundidad por la falta de pruebas, de que ambas maderas sean del mismo genus. Merece la pena destacar que, tal como sucederá más tarde, en los textos de Mattioli y en los comentarios a la obra de Ruel, la confusión entre las dos maderas, guayaco y ébano, se da por el desconocimiento de este último, y no del producto americano, como podría pensarse en un principio También querríamos destacar que Brunfels comienza ya a usar nomenclaturas en diferentes lenguas para catalogar bien los productos, algo que Amato mejorará al poner estos nombres en un epígrafe aparte ${ }^{93}$, por lo que no es difícil pensar en un conocimiento de esta obra por parte de Amato.

En 1535 aparecen publicadas en Basilea las epístolas de Giovanni Manardo, pero la que nos interesa para el asunto que estamos tratando, la $3^{\text {a }}$ epístola del $17^{\circ}$ libro, está datada en la vigilia de S. Mateo (21 de septiembre) de $1532,{ }^{94}$ un año después de la obra de Brunfels. El título de la carta (De Ebeni Indici electione et usu) es elocuente por dos motivos: porque se hace explícita la importancia de la elección de la madera para tratar el mal francés y porque se la denomina ebeni indici. La confusión ya es bastante evidente en Manardo, una de las fuentes de Amato, pues este lo cita explícitamente. En ese momento ya se veía en las boticas guayaco de dos tipos - los que iba a describir Oviedo en su obra aún no publicada en ese momento que probablemente también se confundía en ocasiones con el palo de Brasil ${ }^{95}$. No podemos olvidar, además, que de la tradición pliniana venía el conocimiento de que había una especie de ébano llamado precisamente índico. De modo que Manardo, ante las informaciones confusas, explica lo siguiente:

Tria ad nos hactenus huius ligni genera peruenere. Primum, quod guaiacum uocant, densius, grauius, crassius, interiore parte nigricantius, exteriore subpallida et ueluti lineis

93 Véase, en este mismo volumen, el trabajo de Ana Margarida BorGES, "Léxico científico português nos comentários de Amato: antecedentes e receção".

94 Confirma, además, la fecha, el inicio de la carta, cuando dice que hace 38 años que se padece la enfermedad del mal francés (recuérdese que se suele fechar sus comienzos en 1494, tal como se hacía desde poco después de su aparición): Quum igitur anno hunc duodequadragesimo, ad coercenda humani generis delicta, luem pessimam Gallicam uocatam, ueluti multicipitem hydram, in nos grassari [Deus] premisisset. Cf. Ioannis MANARDUS, Epistolarum medicinalium libri duodeuiginti. Basileae, Hieronymus Artolphus, 1535, p. 377.

95 De hecho, en Johannes Ruellius, De natura stirpium libri tres. Parisiis, Ex officina Simonis Colinaei, 1536, p. 161, Jean Ruel comienza a tratar el palo de Brasil en la entrada del ébano después de haber hablado extensamente del guayaco. 
quibusdam ad fuscum inclinantibus, in aeque distantibus per longum interfecta. Alterius ad albius magis uergit exterior pars, neque est tam manifestis lineis distincta: nigrum tamen et ipsum colorem intrinsecus ostendit, sed minore orbe quam praecedens. Tertium quod sanctum praecipue uocatur, tam intrinsecus quam extrinsecus albicantem colorem prae se fert, exilibusque ualde lineis eius distinguitur longitudo. Ex tribus hisce generibus ego in casu nostro primum praetulerim, quod procul dubio hebenum esse Indicum puto, nec ab eo secundum, nisi forte natalibus, diferre. Tertium ualentius esse non dubito, quoniam et acrius est et odoratius. ${ }^{96}$

Hasta ahora nos han llegado tres tipos de este leño. El primero, al que llaman guayaco, es más denso, más pesado, más grasiento, pero tirando al negro en la parte interior, con la parte externa ligeramente pálida y cortada longitudinalmente, a intervalos regulares, como con ciertas estrías que tienden al moreno. La parte exterior del segundo tiende a una mayor blancura y no está marcada por estrías tan señaladas; sin embargo, muestra una parte interna del mismo color negro, solo que de un diámetro menor que el anterior. El tercero, que es aquel al que de forma especial se llama santo, tanto en la parte interna como en la externa lleva un color blancuzco y su longitud está marcada por hendiduras muy estrechas. De estos tres tipos, para lo que nos ocupa yo preferiría el primero, que sin duda creo que es el ébano índico, y no me parece que el segundo difiera de él a no ser en sus orígenes. No tengo dudas de que el tercero es más fuerte, ya que es más agrio y aromático.

Manardo ya ha identificado, así pues, una especie de guayaco que se encuentra en las boticas con el ébano índico. A partir de este momento se genera una época de confusión en que se bifurcan dos líneas de pensamiento, que podrían estar bien ejemplificadas por dos obras que aparecieron el mismo año, el siguiente a la publicación de las epístolas de Manardo. En 1536 sale publicado, por un lado, el De natura stirpium libri tres de Jean Ruel que ya hemos comentado, y, por otro, el Index Dioscoridis de Amato.

Ruel usa la entrada del ébano para hablar del guayaco y del palo de Brasil, pero solo porque es el único lugar donde será encontrado por sus lectores, que se han ido habituando a buscar esos productos en ese lugar. Ruel es muy consciente de que la semejanza de los dos leños es superficial, y niega categóricamente que se trate de la misma especie (genus) ${ }^{97}$.

En cambio, Amato seguirá la línea opuesta, para afirmar rotundamente que el guayaco es ébano. Puede ser que los motivos económicos no fueran ajenos a esta identificación. Como hemos dicho, el negocio de guayaco movía mucho dinero y ponía en juego sobre el tablero

96 Ioannis MANARDUS, Epistolarum ..., op. cit., p. 378.

97 Cf. Johannes Ruellius, De natura stirpium..., op. cit., p. 161. 
económico de Europa muchos intereses. Los médicos que estuviesen fuera de los circuitos de venta del guayaco, que no sacasen provecho, o miembros de familias de mercaderes, como Amato Lusitano, veían que una mercancía tan valiosa quedaba fuera de su alcance. En ningún otro autor anteriormente se afirma esta identidad con tal pasión, con tal acumulación de argumentos, con tan minuciosa comparación de propiedades. De la extensísima entrada del ébano podemos entresacar algunos fragmentos que nos permitirán ver la convicción de Amato:

Quantum ergo superis de gaiaci beneficio nos debemus, simul et de hebeni nos debere omnes sciant, cum gaiacum lignum vulgo notum antiquorum ebenus est, cum omnia, acsi acu pingerentur, ebeno, quae gaiaco insunt, respondent. ${ }^{98}$

De modo que cuanto debemos a los cielos por los beneficios del guayaco, que todos sepan que lo debemos de igual modo por los del ébano, porque lo que se conoce vulgarmente como palo guayaco es el ébano de los antiguos, ya que todo lo que hay en el guayaco corresponde al ébano como si lo bordaran.

Est vero lignum illud durissimum, ut vix secabilis eius duricies fit, atque ponderosissimum, ut nulla eius quanquam minutissima pars in aqua fluitat aut supernatat, sed omnino mergitur et subcidit, boni (si prunis incendatur) est odoris, a quo gummi subnigrum provenit; nec a se minorem in ebullitione: mittit odorem, boni saporis est atque iucundi, ut tradunt assuetis. His iam verbis manifeste deprehenditur gaiacum lignum antiquorum ebenum esse, cum in omni Dioscoridis descriptioni in praesenti respondet, tam in eius colore quam in reliquis omnibus guaiaco tributis, ut legenti manifestum est. ${ }^{99}$

Este leño es durísimo, tanto que su dureza hace que apenas se pueda cortar, y muy pesado, al punto que ninguna porción de él, ni siquiera la más diminuta, flote en el agua o emerja, sino que se sumerge totalmente y se hunde; si se quema con brasas desprende grato aroma, y de él proviene una resina negruzca; y no es menor lo que sale de él cuando se hierve: emite aroma, es de sabor gustoso y agradable, como se dice en los sitios habituales. Por estas palabras se deduce claramente que el palo guayaco es el ébano de los antiguos, ya que se corresponde totalmente con la descripción de Dioscórides que aquí se presenta, tanto en su color como en todas las demás propiedades atribuidas al guayaco, como le será evidente a quien lo lea.

98 Amatus Lusitanus, Index Dioscoridis..., op. cit., p. 24 r.

99 Amatus Lusitanus, Index Dioscoridis..., op. cit., p. $24 \mathrm{v}$. 
Nec enim ab hac nostra opinione te retrahat id quod in omnium ore est, multa nunc gaiacum possidere, quae minime ebeno prisci tribuerunt. Nam licet notitiam de eo olim habuere, non tamen exactam ut nos. ${ }^{100}$

Y que no te aparte de esta opinión nuestra lo que está en boca de todo el mundo, que el guayacán posee ahora muchas propiedades que los antiguos no atribuyeron en absoluto al ébano. Porque si bien tuvieron entonces noticia de aquel, no con precisión, como nosotros.

Creemos que esta pequeña muestra de fragmentos de esta entrada basta para demostrar lo que decíamos. La opinión de Amato es, así pues, tajante, decidida, diríamos que valiente, a pesar de su error. El joven de 25 años quiere parecerse a Leoniceno y Manardo, sus maestros, y por eso no tiene miedo de lanzar sus opiniones, aunque sean osadas:

Quibus heroibus quicquid scimus, si modo quid scimus, acceptum referentes atque $a b$ ipsorum perennibus fontibus, parvos nostros cantharos adimplentes, hoc opus componere sumus aggressi. Sed quum ipsi non sine ingenti laude quid de unaquaque re sentirent audacter nec minus erudite praeferrent, non video quur mihi vitio sit vertendum, si quid de hebeno nostrum iuditium aperiamus, cum ille ab omnibus ferme prae manibus habeatur, nec tamen quid apud antiquos fuerit sciatur. ${ }^{101}$

Señalando que hemos recibido todo lo que sabemos, si es que sabemos algo, de estos héroes, y llenando nuestros pequeños cántaros de sus fuentes perpetuas, nos decidimos a componer esta obra. Pero dado que ellos reciben grandes alabanzas cuando presentan lo que opinan de cada cosa de forma audaz y no menos erudita, no veo por qué se habría de considerar en mí un defecto si mostramos un poco nuestra opinión sobre el ébano, ya que casi todos lo manipulan pero no se sabe qué era para los antiguos.

Poco después, algunos médicos eruditos reaccionarán con decisión y de forma contundente contra esta opinión. En 1538, Alfonso Ferri, el cirujano mayor del papa Pablo III ${ }^{102}$ y en 1540 Antonio Gallo ${ }^{103}$, publican sendos textos que incluyen demostraciones contundentes sobre la diferencia entre el ébano y el guayaco. No sería imposible que el texto de Amato hubiera tenido algo que ver con esta reacción. Como hemos visto, el texto de Ruel no identificaba ambos

100 Amatus Lusitanus, Index Dioscoridis..., op. cit., p. 25v.

101 Amatus Lusitanus, Index Dioscoridis..., op. cit., p. $24 \mathrm{r}$.

102 Alfonsus FERRI, De ligni sancti multiplici medicina et vini exhibitione libri quatuor. Basileiae, Johannes Bebelius, 1538.

103 Antonius Gallus, De ligno sancto non permiscendo. Parisiis, Apud Simonem Colinaeum, 1540. 
productos, como tampoco lo hizo en 1537 Antonio Musa Brassavola, ${ }^{104}$ por lo que no pueden haber provocado los escritos de corrección. Es probable que el prestigio de Manardo y la escuela de Ferrara, y ver que un joven seguidor ${ }^{105}$, ciertamente prometedor, se alzaba como adalid de la causa de la identificación, desencadenase esta reacción científica que intentó poner las cosas en su sitio y evitar que se vendiera ébano en lugar de guayaco. Lo cierto era que, irónicamente, ninguno de los dos tendría más éxito en el tratamiento del mal francés que el otro.

La ciencia se va construyendo así paso a paso, e incluso cuando esos pasos van en la dirección equivocada, no por ello se deja de construir ciencia, pues las conclusiones y el debate posterior servirán para un avance más. Hemos visto que la confluencia de diversos factores: la aparición de una nueva enfermedad, las dificultades en describir esa nueva dolencia, las características de la historia natural, las descripciones de nuevos productos, determinados intereses económicos, la circulación de la información, etc., va determinando el momento en que se produce la identificación, científicamente comprobada, aunque equivocada, entre dos especies de árboles de características semejantes. En ese proceso, el joven João Rodrigues de Castelo Branco, aún no Amato Lusitano, tuvo un papel relevante que merece tenerse en consideración.

\section{BIBLIOGRAFÍA}

Amatus Lusitanus (João Rodrigues de Castelo Branco), Index Dioscoridis. Antuerpiae, excudebat Vidua Martini Caesaris, 1536.

Amatus Lusitanus, In Dioscoridis Anazarbei de medica materia libros quinque enarrationes eruditissimae. Venetiis, apud Gualterum Scotum, 1553.

Andrade, António Manuel Lopes, "Ciência, Negócio e Religião: Amato Lusitano em Antuérpia”, en Inês de Ornellas e Castro, Vanda Anastácio (coord.), Revisitar os Saberes - Referências Clássicas na Cultura Portuguesa do Renascimento à Época Moderna. Lisboa, Centro de Estudos Clássicos - Faculdade de Letras da Universidade de Lisboa, 2010, pp. 9-49.

104 Antonius Musa Brasavolus, Examen omnium simplicium medicamentorum quorum in officinis usus est. Lugduni, Apud Ioannem et Franciscum Frellaeos, fratres, 1537. Cf. p. 328: Quandoque hebeni speciem esse suspicabamur, sed postea autores considerantes, a suspicione liberati sumus.

105 Unos años más tarde, Amato mantendría estrechas relaciones con los miembros de la escuela de Ferrara, sobre todo tras su llegada a esta ciudad a mediados de 1540, donde ejercería, a partir del año siguiente, funciones de profesor de medicina teorica en su Estudio. Cf. António Manuel Lopes ANDRADE, "Dioscórides renovado pela mão dos humanistas: os comentários de Amato Lusitano", en Carmen SOARES (Coord.), Espaços do Pensamento Científico da Antiguidade. Volume I. Coimbra, Imprensa da Universidade de Coimbra, 2013, pp. 71-90. 
Andrade, António Manuel Lopes, "Dioscórides renovado pela mão dos humanistas: os comentários de Amato Lusitano”, en Carmen Soares (Coord.), Espaços do Pensamento Cientifico da Antiguidade. Volume I. Coimbra, Imprensa da Universidade de Coimbra, 2013, pp. 71-90.

Arrizabalaga, Jon, "Práctica y teoría en la medicina universitaria de finales del siglo xv: el tratamiento del mal francés en la corte papal de Alejandro VI Borgia”, Arbor 153, no 604-605 (Abril-Mayo 1996), pp.127-160.

Arrizabalaga, Jon, “Sebastiano dall'Aquila (c. 1440 - c. 1510), el 'mal francés' y la 'disputa de Ferrara' (1497)”, DYNAMIS. Acta Hispanica ad Medicinae Scientiarumque Historiam Illustrandam 14 (1994), pp. 227-247. Arrizabalaga, Jon, "Syphilis", The Cambridge World History of Human Disease. $1^{\text {st }}$ ed. Cambridge, Cambridge University Press, 1993, pp. 1025-1033. Cambridge Histories Online. Accedido el 16 de marzo de 2013. http://dx.doi.org/10.1017/CHOL9780521332866.

Arrizabalaga, Jon, Henderson, John \& French, Roger, The Great Pox. The French Disease in Renaissance Europe. New Haven and London, Yale University Press, 1997.

[Barlandus, Hubertus], Pedanii Dioscoridis Anarzabei de medicinali materia libri sex, Ioanne Ruellio Suessionensi interprete, cuilibet capiti additae annotationes, eruditae et compendiariae e selectiori medicorum promptuario. Lugduni, Apud Balthazarem Arnolletum, 1550.

BenzInG, Josef, Ulrich von Hutten und seine Drucker: eine Bibliographie der Schriften Huttens im 16. Jahrhundert, mit Beiträgen von Heinrich Grimm. Wiesbaden, Otto Harrassowitz, 1956.

Brasavolus, Antonius Musa, Examen omnium simplicium medicamentorum quorum in officinis usus est. Lugduni, Apud Ioannem et Franciscum Frellaeos, fratres, 1537.

Brunfels, Otto, Noui Herbarii Tomus II, per Oth[o] Brunf[elsio] recens editus. Argentorati, Apud Ioannem Scottum, 1531.

Bubnova, Tatiana, "Delicado en la Peña de Martos", en Jules Whicker, Actas de XII Congreso de la Asociación Internacional de Hispanistas 21-26 de agosto de 1995, Vol. 2: Estudios áureos I. Birmingham, University of Birmingham, 1998, pp. 70-78. Disponible en http://cvc.cervantes.es/literatura/aih/pdf/12/ aih_12_2_011.pdf.

Delgado, Francisco, Retrato de la lozana andaluza. Madrid, Imprenta y Estereotipia de M. Rivadeneyra, 1871.

Chinchilla, Anastasio, Anales históricos de la medicina en general y biográfico-bibliográficos de la española en particular, Tomo I. Valencia, Imprenta de López y Compañía, 1841.

Cipriani, Mariano, "Mercurio e mercurialisti, guaiaco e guaiacofili e 'fenomeno Fugger”, Rivista di Storia della Medicina 6 (1962), pp. 87-113.

Colón Doménech, Germán, "Filología y sífilis. Sobre el mal de simiente o mal de sement", Revista de Filología Española 78, 30-4o (julio-diciembre de 1998), pp. 275-308.

Corradi, Alfonso, Nuovi documenti per la storia delle malattie veneree in Italia dalla fine del Quatrocento alla metà del Cinquecento. Milano, Tipografia Fratelli Rechiedei, 1884.

Damiani, Bruno M., "Francisco Delicado El modo de adoperare el legno de India Occidentale. A critical transcription”, Revista Hispánica Moderna 36, no 4 (1970/1971), pp. 251-271. 
Dins, João José Alves, Amato Lusitano e a sua obra: séculos xvi e Xvir. Lisboa, Biblioteca Nacional de Portugal, 2011.

Egnatil, Ioannis Baptistæ, In Dioscoridem ab Hermolao Barbaro tralatum annotamenta. [Venetiis], Aloisius \& Franciscus Barbari \& Ioannes Bartholomaeus Astensis, [1516].

Eyn bewert Recept wie man das holtz Guagacan fur die kranckheyt Frantzosen brauchen sol etcetera. Nürnberg, Hieronymus Höltzel, 1518. http://daten.digitale-sammlungen.de/bsb00083987/image_1.

Fernández de Oviedo, Gonzalo, Historia general y natural de las Indias, islas y Tierra-Firme del mar Océano, editada por D. José Amador de los Ríos para la Real Academia de la Historia. Primera parte. Madrid, Imprenta de la Real Academia de la Historia, 1851.

Fernández de Oviedo, Gonzalo, Sumario de la natural y general historia de las Indias. Toledo, Ramón de Petrás, 1526.

Ferri, Alfonsus, De ligni sancti multiplici medicina et vini exhibitione libri quatuor. Basileiae, Johannes Bebelius, 1538.

Fisch, Max Harold and Schullian, Dorothy May, Nicolaus Pol doctor 1494: with a critical text of his guaiac tract. New York, Herbert Reichner for Cleveland Medical Library Association 1947.

Fracastor, Jerôme, La syphilis ou le mal français. Syphilis sive Morbus Gallicus, Texte établi, traduit, présenté et annoté sous la direction de Jacqueline Vons, avec la collaboration de Concetta Pennuto et Danielle Gourevitch et le concours du Dr. Jacques Chevaluier. Paris, Les Belles Lettres, 2011.

Fracastorius, Hieronymus, De contagione et contagiosis morbis et eorum curatione, libri III. Translation and notes by Wilmer Cave Wright, Ph.D.. New York-London, G. P. Putnam’s Sons, 1930.

Gallus, Antonius, De ligno sancto non permiscendo. Parisiis, Apud Simonem Colinaeum, 1540.

González Bueno, Antonio "El Descubrimiento de la Naturaleza del Nuevo Mundo: Las Plantas Americanas en la Europa del siglo xvi", Circumscribere. International Journal for the History of Science 2 (2007), pp. 10-25, http://revistas.pucsp.br/index.php/circumhc/article/view/569/1028.

González Bueno, Antonio, "La flora del paraíso: recepción de las plantas americanas en la literatura científica europea del Renacimiento” en Alfredo Baratas (ed.), Memorias de la Real Sociedad Española de Historia Natural. Tomo III. 2a época. El libro de la Naturaleza. Madrid, Facultades de Biología y Geología - Ciudad Universitaria, 2004, pp. 5-33.

González Manjarrés, Miguel Ángel, Andrés Laguna y el Humanismo médico. Salamanca, Junta de Castilla y León, 2000.

Gourevitch, Danielle, "La syphilis, une maladie aux noms multiples" en Jerôme Fracastor, La syphilis ou le mal français. Syphilis sive Morbus Gallicus, Texte établi, traduit, présenté et annoté sous la direction de Jacqueline Vons, avec la collaboration de Concetta Pennuto et Danielle Gourevitch et le concours du Dr. Jacques Chevallier. Paris, Les Belles Lettres, 2011, pp. Xv-XXXVII.

Häberlein, Mark, The Fuggers of Augsburg. Pursuing Wealth and Honor in Renaissance Germany. Charlottesville \& London, University of Virginia Press, 2012 (= Die Fugger: Geschichte einer Augsburger Familie, 1367-1650. Stuttgart, W. Kohlhammer GmbH, 2006). 
Henderson, John, "Fracastoro, il legno santo e la cura del 'mal francese", en Alessandro Pastore e Enrico Peruzzi (eds.), Girolamo Fracastoro. Fra medicina, filosofia e scienze della natura. Atti del Convegno internazionale di studi in occasione del 450 anniversario della morte. Verona-Padova 9-11 ottobre 2003. Firenze, Leo S. Olschki, 2006, pp. 73-89.

Herrero Ingelmo, Ma Cruz; Montero Cartelle, Enrique, "El Morbus gallicus o Mal francés en La Lozana andaluza de Francisco Delicado", Asclepio 65, 2 (julio-diciembre 2013), p021. http://dx.doi. org/10.3989/asclepio.2013.21.

Hutten, Ulrich von, De guaiaci medicina et morbo Gallico liber unus. [Parisiis], Ex typis Petri Vidoue, 1519.

Kusukawa, Sachiko, Picturing the Book of Nature. Image, Text, and Argument in Sixteenth-Century Human Anatomy and Medical Botany. Chicago, University of Chicago Press, 2012.

Laguna, Andrés, Annotationes in Dioscoridem Anazarbeum, per Andream Lacunam Segobiensem Medicum Iulii III Pont[tificis] Max[imi] iuxta vetustissimorum codicum fidem elaboratae. Lugduni, Apud Gulielmum Rouillium, 1554.

Liber de morbo Gallico in quo diversi celeberrimi in tale materia scribentes medicine continentur auctores. Veneza, [Giovanni Padovano \& Venturino Ruffinelli], 1535.

López Piñero, José María y López Terrada, María Luz, La influencia española en la introducción en Europa de las plantas americanas (1493-1623). Cuadernos valencianos de Historia de la medicina y de la ciencia LIII. Serie A (monografías). Valencia, Instituto de Estudios Documentales e Históricos sobre la Ciencia, 1997. Disponible en http://digital.csic.es/bitstream/10261/88589/1/P_AMER_completo.pdf.

López Piñero, José María, Medicina e historia natural en la sociedad española de los siglos XVI y XviI. Valencia, Universitat de València, 2007.

Luisinus, Aloysius, De morbo gallico omnia quae extant apud omnes medicos cuiusque nationis, tomus prior. Venetiis, apud Iordanum Zilettum, 1566.

Manardus, Ioannis, Epistolarum medicinalium libri duodeuiginti. Basileae, Hieronymus Artolphus, 1535.

Martyr ab Angleria, Petrus, De rebus Oceanicis et Orbe nouo decades tres. Basileae, apud Ioannem Bebelium, 1533.

Mattioli, Pietro Andrea, Commentarii in libros sex Pedacii Dioscoridis Anazarbei de medica materia. Adiectis quam plurimis plantarum et animalium imaginibus, eodem authore. Venetiis, in officina Erasmiana, apud Vincentium Valgrisium, 1554.

Munger, Robert S., "Guaiacum, the Holy Wood of the New World", Journal of the History of Medicine and allied Sciences 4 (1949), pp. 196-229.

Olgilvie, Brian W., The Science of Describing. Natural History in Renaissance Europe. Chicago and London, The Universtity of Chicago Press, 2006.

Orta, Garcia de, Colóquios dos simples e drogas da Índia, ed. Conde de Ficalho, 2 vols. Lisboa, Imprensa Nacional, 1985.

PArdo Tomás, José, “Obras españolas sobre historia natural y materia médica americanas en la Italia del siglo xvi”, Asclepio 43.1 (1991), pp. 51-94. 
Pardo Tomás, José y López Terrada, María Luz, Las primeras noticias sobre plantas americanas en las relaciones de viajes y crónicas de Indias (1493-1553). Cuadernos valencianos de Historia de la medicina y de la ciencia XL. Serie A (monografías). Valencia, Instituto de Estudios Documentales e Históricos sobre la Ciencia, 1993.

Pérez IbÁŃñez, Ma Jesús, "Galli vocant istum morbum morbum eius cuius est. Otra designación para el 'mal francés', Asclepio. Revista de Historia de la Medicina y de la Ciencia 40, no 1 (enero-junio 2008), pp. $267-280$.

Pérez Ibáñez, Maa Jesús, “Un problema médico y terminológico (sífilis en el s. Xvi), Voces 6 (1995), pp. 61-79.

Роттоn, F.F.A., Livre du chevalier allemand Ulric de Hutten sur la maladie fançaise et sur les propriétés du bois de Gayac. Orné d'un portrait de l'auteur, précédé d'une notice historique sur sa vie et ses ouvrages. Lyon, Imprimerie de Louis Perrin, 1865.

Riddle, John M., “Dioscorides”, en F. Edward Cranz (ed.), Paul Oskar Kristeller (assoc. ed.), Catalogus Translationum et Commentariorum: Mediaeval and Renaissance Latin Translations and Commentaries. Annotated Lists and Guides, Vol. IV. Washington D. C., The Catholic University of America Press, 1980, pp. 1-144.

Ruellius, Johannes, De natura stirpium libri tres. Parisiis, Ex officina Simonis Colinaei, 1536.

Schmaus, Leonard, Lucubratiuncula de morbo Gallico et cura eius nouiter reperta cum ligno Indico Leonardi Schmaus medicine professoris. Augsburg, Grimm \& Wirsung, 1518.

Tagarelli, Antonio; Tagarelli, Giuseppe; Lagonia, Paolo; Piro, Anna, "A Brief History of Syphilis by Its Synonyms", Acta Dermatovenerol Croat 19-4 (2011), pp. 228-236.

Textor, Benedictus, Stirpium differentiae ex Dioscoride secundum locos communes. Opus ad ipsarum plantarum cognitionem admodum conducibile. Parisiis, Apud Simonem Colinaeum, 1534.

Torre Revello, José, "Pedro Mártir de Anglería y su obra De orbe nouo", Thesaurus: boletín del Instituto Caro y Cuervo 12 (1-3), pp. 133-153. 
A partir dos alvores do século XVI, a matéria médica torna-se indiscutivelmente um tema de primeira grandeza entre os membros da República das Letras, objecto de estudo e de controvérsia entre os mais notáveis humanistas europeus, em particular entre os cultores da arte médica. Entre os autores em destaque neste volume encontram-se, à cabeça, os nomes de Amato Lusitano, Garcia de Orta e Nicolás Monardes, famosos pelos contributos valiosos que deram para o conhecimento do mundo natural. 0 volume encontra-se dividido em duas partes: a primeira, subordinada ao título "Humanismo e Ciência", alberga os estudos que versam sobre todos os autores estudados, à excepção de Amato Lusitano; a segunda está reservada a um conjunto de trabalhos dedicados exclusivamente ao médico albicastrense, cuja autoria se fica a dever, em boa parte, aos membros da equipa do projecto de I\&D "Dioscórides e o Humanismo Português: os Comentários de Amato Lusitano", tomando, por isso, 0 seu próprio título. Nesta segunda parte, oferece-se, desde já, aos leitores uma amostra significativa do trabalho desenvolvido no âmbito do projecto e que culminará, assim se espera, na edição e tradução integral para língua portuguesa das quatro obras previstas de Dioscórides, Amato Lusitano e Pietro Andrea Mattioli. 
